NBER WORKING PAPER SERIES

\title{
THE SOURCES OF FLUCTUATIONS IN AGGREGATE INVENTORIES AND GNP
}

Kenneth D. West

Working Paper No. 2992

\author{
NATIONAL BUREAU OF ECONOMIC RESEARCH \\ 1050 Massachusetts Avenue \\ Cambridge, MA 02138 \\ June, 1989
}

I thank Ben Bernanke, Olivier Blanchard, Alan Blinder, Ray Fair, James Hamilton, Tryphon Kollintzas and participants in several seminars for helpful comments and discussions, and the Bradley Foundation and the National Science Foundation for financial support. This paper is part of NBER's research program in Economic Fluctuations. Any opinions expressed are those of the author not those of the National Bureau of Economic Research. 
NBER Working Paper \#2992

June 1989

\title{
THE SOURCES OF FLUCTUATIONS IN AGGREGATE \\ INVENTORIES AND GNP
}

\begin{abstract}
A simple real linear-quadratic inventory model is used to determine how cost and demand shocks interacted to cause fluctuations in aggregate GNP and inventories in the U.S., 1947-1986. Cost shocks appear to be the predominant source of fluctuations in inventories, and are largely responsible for the well known fact that GNP is more variable than final sales. Cost and demand shocks are of roughly equal importance for GNP. These estimates are, however, imprecise. With a different, but plausible, value for a certain target inventory-sales ratio, cost shocks are less important than demand shocks for GNP fluctuations.
\end{abstract}

Kenneth D. West

Department of Economics University of Wisconsin 1180 Observatory Drive Madison, WI 53706 


\section{Introduction}

Th1s paper is concerned with how real cost and demand shocks interact to determine aggregate real Inventories and GNP in the postwar United States. Its aim 1s to answer such questions as: Do inventorles respond wainly to demand shocks (Holt et al. (1960)? Are demand shocks of secondary importance in explaining fluctuations in GNP (Prescott $[1986 \mathrm{a}, \mathrm{b}]$ )? What is the dynamic pattern of the response of Inventorles to cost and demand shocks? Of GNP (Blanchard and Quah [1988])?

A long tradition attributes the bulk of movements in inventorles to demand shocks. Accelerator models, ploneered by Metzler [1941] and Lovell [1961], posit that inventorles are proportional to expected sales. Production smoothing models, ploneered by Holt et al. [1960], suggest that because of Increasing marginal costs of production, the desire to smooth production relative to demand will also cause adjustment of inventorles in response to demand.

Some recent evidence has, however, suggested that Inventorles may also (or Instead) be responding to cost shocks. One simple styllzed fact that suggests this is that for virtually any U. S. Industry or aggregate, production is more variable than demand (BIInder [1981, 1986a], Blanchard [1983]). ${ }^{1}$ This is logically Inconsistent with a simple production smoothing model with increasing production and Inventory costs, because such a model argues that the sole reason to hold Inventorles is to smooth production relative to demand (West (1986]). It is also empirically inconsistent with more complex production smoothing models that allow for accelerator effects and for quadratic costs of changing production, since these additional complexities do not appear to explain the excess varlability (West [1986]).

Cost shocks, however, rationalize the excess production varlability quite naturally. This is most easily seen in an extrene case when demand is constant 
(there are no denand shocks). Production w111 st111 vary as costs vary, since production will be hlgh (low) when costs are low (hlgh), with procyclical adjustment of Inventorles covering the gap between production and sales. Production will therefore be more varlable than sales.

Partly because cost shocks provide a simple explanation of the excess varlablilty of production, recent Inventory research has emphasized the potential role of cost shocks (e.g., BIInder [1986b], Macc1n1 and Rossana [1984], Miron and Zeldes (1987]), It appears, however, that there 1s as yet no direct evidence, still less a consensus, on how Important cost shocks are relative to demand shocks. Christlano and Elchenbaum [1987], for example, find the excess variability of production suggestive of a predominant role for cost shocks, while Blinder [1986a] constructs an example in whlch the excess varlabllity is consistent with a very small role. As stated above, one aim of this paper is to quantify the relative importance of cost and demand shocks as determinants of aggregate Inventories.

Simultaneously, the paper studies hov these shocks Interact to determine GNP. Recent work in real business cycles has argued that most of the movements in GNP can be explained by fluctuations in costs. Prescott [1986a], for example, suggests that 75 percent of these movements are cost related. Consistent with this, two very recent vector autoregressive (VAR) studles have found that well over half of the varlance of GNP forecasts more than twelve quarters ahead is due to permanent rather than trans1tory shocks (Blanchard and Quah [1988], KIng et a1. [1987]); both studies Interpret permanont shocks as cost rather than demand related, whlle acknowledging that other Interpretations are possible. By contrast, an earller VAR study (Blanchard and Watson (1986]) found that demand shocks are the primary source of GNP fluctuations, as did a recent study by Falr [1988].

The present paper uses comovements of Inventorles and GNP to help determine the sources of fluctuations in GNP. GIven the Ioportance of movements of inventory 
stocks at cyclical turning points (Blinder [1981], Blinder and Holtz-Eakin [1986]), this seens likely to contain significant information about the sources of U. S. business cycles. The basic intultion is suggested by a simple production smoothing model, where the only cost terms are ones quadratic in the level of production and Inventories: demand shocks w11l tend to cause inventories to move countercyclically, cost shocks w11l tend to cause them to move procyclically.

Since it is well known that inventory movements are procyclical (Summers [1981]), this simple model would, of course, attribute much of the movement in GNP and Inventories to cost shocks. The model used, however, allows for a target Inventory-sales ratlo (as does, e.g., Blanchard [1983], Ramey [1988] and West [1986]). This can induce procyclical movewents in Inventories in response to demand shocks, and no simple mapping between shocks and comovements is expected to obtain. But estimation of the parameter that determines the target inventory-sales ratio, together with the other parameters of the model, allows one to disentangle movements due to cost from those due to demand shocks. These parameters may be computed from the estimates of a bivarlate VAR in inventories and GNP. The VAR is estimated on quarterly data, 1947-1986, for both stationary and unit root specifications.

The point estimates suggest that cost shocks are the predominant source of fluctuations in inventorles. They are largely though not exclusively the reason that GNP is more varlable than final sales; some excess variability appears to be due as well to increasing returns in production. Cost and demand shocks are of roughly equal inportance in GNP fluctuations. Cost shocks are especlally important for Inventorles at relatively long horizons, for GNP at short horizons. Over 90 percent of the variance of inventory forecasts 20 quarters ahead $1 \mathrm{~s}$ due to cost shocks. The comparable figure for GNP is about 40 to 60 percent.

GNP and Inventories both display hump shaped responses to both demand and cost shocks, with the peak affect occurring about four quarters out. When the shocks are 
assumed to have unit roots, new steady states are essentially achieved in about ten to twelve quarters; when the shocks are assumed stationary, the varlables are narkedly different from the steady state even forty quarters out.

For the usual reasons, however, these results should be interpreted with caution: tests of overidentifying restrictions strongly reject the model (as in Christiano and Eichenbaum [1987], for example), and confidence intervals are rather large (as in Blanchard and Quah [1988], for example). In connection with the latter point, it should be noted that the estimates are quite sensitive to the parameter that determines the target inventory-sales ratio. The point estimate of the relevant parameter is lower than that obtained in some previous studies (e.g., Blanchard [1983], Ramey (1988], West [1986]). When this parameter is constrained to a higher value consistent with these previous studies, much less--only about 10 per cent-. of the movement in GNP over 20 quarters ahead is attributed to cost shocks.

Section II describes the model. Section III presents empirical results. Section IV concludes. An appendix has some technical details, with an additional appendix avallable on request from the author containing additional results and details not of central importance.

\section{Model}

The basic model is a generalization of the linear-quadratic inventory models In, for example, Blinder [1982], Blanchard [1983], Belsley [1969], and West [1986], and was suggested by Sargent [1979, ch. XVI]. A similar model was developed independently by Christiano and Eichenbaum [1987]. To focus on interactions between inventories and output fluctuations, it is assumed that storage in inventories is the only means of smoothing production or demand in response to shocks. Demand is linear (the area under the demand curve is quadratic). Production and storage costs also are quadratic. 
Let $S_{z}$ be real demand (sales), $Q_{t}$ real production, $H_{t}$ real inventories. The varlables are linked by the Identity $Q_{t}-S_{t}+\Delta H_{t}$. Let $L_{t}$ be labor supply, $P_{t}$ the real price of output, $R_{c}$ real profits, with the wage rate the numeralre.

Utility is separable over time. The per period utility function of the representative consumer depends on labor and current consumption $s_{t}$ :

$$
-\mathrm{fL}_{\mathrm{z}} \cdot \mathrm{f}_{\mathrm{gos}} \mathrm{S}_{\mathrm{t}}^{2}+2 \mathrm{fU}_{\mathrm{dt}} S_{\mathrm{t}} \text {. }
$$

In (1), f and $g_{0 s}$ are positive, and $U_{d t}$ is a demand shock. Constant and linear terms In (1) and throughout are suppressed, for notational simplicity. The first term in (1) reflects disutility from work, the second diminishing marginal benefit of additional demand. The demand shock $U_{d t}$ captures shocks to preferences, policy, and the like. A positive value raises demand.

For the representative firm, production and storage costs $L_{t}=C_{t}$ are

(2) $C_{t}=B_{0 Q} Q_{t}^{2}+g_{10} \Delta Q_{t}^{2}+g_{0 B}\left(H_{t-1}-g_{E S} S_{t}\right)^{2}+2 U_{e t}\left(h H_{t}+Q_{t}\right)$.

In (1), $h$ and $g_{E s}$ are positive and the other $g$.. parameters are such that the maximization problem stated below is well defined (see footnote 3 below); $U_{c t}$ is a cost shock; $E_{q}$ is mathematical expectations (linear projections) conditional on period $t$ information.

The first term in (2) reflects increasing costs to production if goo $>0$, decreasing costs if $g_{00}<0$. The second term reflects costs of adjusting production (e.g., hiring and firing costs). Simple forms of costs of adjustment are often assumed present in inventory models (e.g., Eichenbaum [1984], Maccini and Rossana [1981, 1984]). The quadratic specification can be considered an approximation co an arbitrary cost function that is convex in production. The accelerator term, 
$\mathrm{g}_{0 \mathrm{~B}}\left(\mathrm{H}_{\mathrm{t}-1}-\mathrm{g}_{\mathrm{BS}} \mathrm{S}_{\mathrm{t}}\right)^{2}$ appears in many studies of manufacturing and retail inventories (e.g., Blanchard [1983], Irvine (1981]). It reflects a balancing of inventory holding and stockout costs (Holt et al. [1960]), capturing a tendency of inventories to track a target level $g_{a s} S_{t}$, and $g_{a s}$ is the target inventory-sales ratio that was mentioned in the introduction. See Blanchard [1983] or West [1986] for additional discussion of this and the other terms in the cost function.

A positive cost shock $U_{c t}$ ralses the cost of both production and inventory storage. The parameter h measures the shock's Impact on inventory storage costs relative to its impact on production costs. The shock captures random fluctuations in technology.

The representative consumer maximizes the expected present discounted value of utility, the representative firm the expected present discounted value of profits, using a common discount rate $b, 0<b<1$ :

(3) $\max$ IIf $I--\infty E_{0} \sum_{t=0}^{T} b^{t}\left(-E_{L}-f_{g_{0 S}} S_{t}{ }^{2}+2 f U_{d t} S_{t}\right) \quad$ s.t. $P_{t} S_{t}-L_{t}+R_{t}$,

(4) $\max 11 \mathrm{~m} I--\infty E_{0} \Sigma_{t-\infty}^{T} b^{t} R_{t}$

$$
\text { s.t. } \begin{aligned}
R_{t} & =P_{t} S_{t}-L_{t}, \\
L_{t} & =C_{t}, S_{t}-Q_{t}-\Delta H_{t} .
\end{aligned}
$$

The constraints in (3) and (4) assume that all profits are remitted to consumers as profits are earned.

The nodel is solved as follows. Tentatively assume that all markets are competitive. Set the number of firms and consumers to one. Use $P_{t} S_{t}=L_{q}+R_{t}$ to eliminate $L_{c}$ from ( 3 ).

(5) $\max$ IIm $I \rightarrow E_{0} \Sigma_{t=0}^{T} b^{t}\left[-f\left(P_{t} S_{t}-R_{t}\right)-E_{g_{0 S}} S_{t}{ }^{2}+2 f U_{d t} S_{t}\right]$ 
Differentiate with respect to $s_{t}$. The resulting first order condition may be written as an aggregate demand curve

(6) $P_{t}=-2 g_{0 s} S_{t}+2 U_{d t}$.

For the $f i r m$, use $S_{t}-Q_{t}-\Delta H_{t}$ to write the sum in (4) in terms of $h_{t}$ and $Q_{t}$. Let $c_{t}=E_{t} \Sigma_{j=0} b^{J} C_{t+j}$. Differentiate with respect to $H_{t}$ and $Q_{t}$. The resulting first order conditions may be written

$$
\begin{aligned}
& -P_{t}+b E_{t} P_{t+1}=\quad \partial c_{t} / \partial H_{t}-2 g_{08 B g s}\left(H_{t-1}-g_{B s} S_{t}\right)+ \\
& 2 b_{\text {oH }}\left(1-g_{A B}\right)\left(H_{t}-g_{A B} E_{t} S_{t+1}\right)+2 h U_{c t} \text {. } \\
& P_{t}=\partial c_{t} / \partial Q_{t}=-2 b g_{10} E_{t} Q_{t+1}+2\left[g_{00}+(1+b) g_{10}\right] Q_{t} \\
& -2 g_{1 Q} Q_{t-1}=g_{0 B} g_{A B}\left(H_{t-1}-g_{e s} S_{t}\right)+2 U_{c t} \text {. }
\end{aligned}
$$

The first equation in (7) says that the firm is indifferent between adding a unit to inventory this perlod to be sold next perlod (excess of discounted expected revenue over cost is $b E_{t} P_{t+1}-\partial c_{t} / \partial H_{t}$ ) and selling the unit this perlod (revenue is $P_{t}$ ). The second equation in (7) says that the $f 1 \mathrm{rm}$ produces unt 11 marginal production cost equals price. See or Blanchard and Melino [1986] for additional interpretation.

Equilibrium $P_{t}, Q_{t}, S_{t}$ and $H_{t}$ are determined by the three equations in (6) and (7) and the identity $Q_{t}-S_{t}+\Delta H_{t}$. The equilibrium is perturbed as demand shocks shift the aggregate denand curve (6), cost shocks shift the aggregate inventory and output supply curves (7). To estimate how the shocks interact to determine $Q_{t}, H_{t}$ and $S_{t}$, it is conventent to eliminate $P_{t}$ and $E_{t} P_{t+1}$ from (7) by substituting (6) and (6) led one time perlod into $(7)$. Let $Y_{t}$ be the $(2 \times 1)$ vector $\left(H_{t} Q_{t}\right)$. It follows from stralghtforward algebra that the resulting first order condition is 
(8) $E_{t}\left[b A_{1} Y_{t+1}+A_{0} Y_{t}+A_{1} Y_{t-1}+\beta_{0}^{-1}\left(D_{0} U_{t}+b D_{1} U_{t+1}\right)\right]=0$.

In (8), $B_{0}=\mathrm{B}_{0 S}+\mathrm{g}_{00}+\mathrm{B}_{08} \mathrm{~B}_{E S}{ }^{2}+(1+b) B_{1 Q} ; A_{0}$ and $A_{1}$ are $2 \times 2$ matrices that depend on the discount rate $b$ and the parameters in (1) and (2), with $A_{0}$ symmetric and positive definite, with nonzero off-diagonal elements,

$$
A_{0}=\left|\begin{array}{ll}
\beta_{2} & \beta_{1} \\
\beta_{1} & 1
\end{array}\right|, \quad A_{1}=\left|\begin{array}{cc}
\beta_{4} & 0 \\
-\beta_{4} & \beta_{3}
\end{array}\right| \text {. }
$$

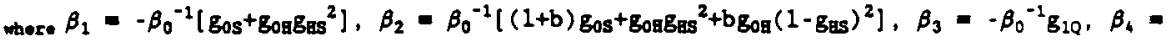
$-\beta_{0}^{-1}\left[g_{0 S}-g_{08 B} g_{E S}\left(1-g_{E s}\right)\right] ; U_{\varepsilon}$ is the $2 \times 1$ vector $\left(U_{c t}, U_{d t}\right)^{\prime} ;$ the $D_{1}$ are $2 \times 2$ matrices,

$$
D_{0}=\left|\begin{array}{rr}
h & 1 \\
1 & -1
\end{array}\right| . \quad D_{1}-\left|\begin{array}{rr}
0 & -1 \\
0 & 0
\end{array}\right| .
$$

Equation (8) may be interpreted by noting that the competitive market structure so far assumed solves a social planning problem of maximizing the expected present discounted value of the excess of consumers surplus over production and storage costs :

$$
\begin{array}{cc}
\max 1 \text { im } t-\rightarrow E_{0} \sum_{t=0}^{T} b^{t}\left(W_{t} *-C_{t}\right) \quad \text { s.t. } W_{t} *-\cdot g_{0 S} s_{t}{ }^{2}+2 U_{d t} s_{t}, \\
Q_{t}-s_{t}+\Delta H_{t} .
\end{array}
$$

Equation (8) says that one can increase this value neither by selling one fewer unit this period, carrying the extra unit in inventory and selling it next period, nor by producing and selling one extra unit this period.

Equation (8) was derived under the assumption that the product market is competitive. Suppose instead that a single firm is a monopolist, as in Blinder [1982]. It is straightforward to verify that (8) still holds, 1.e., the 
monopolistic and perfectly competitive versions of the model are observationally equivalent. The analysis below therefore is robust to possible imperfection in the product market, and allows sticky prices in the sense of Blinder [1982].2

Regardless of the structure of the product market, the reduced form solution to (8) depends on the stochastic process followed by the shock $U_{t}$. The empirical work assumes that the cost and demand shocks follow uncorrelated AR(1) (possibly random walk) processes with parameters $\phi_{c}$ and $\phi_{d}$, with $\left|\phi_{d}\right|,\left|\phi_{d}\right| \leq 1: E_{t-1} U_{d t}-\phi_{d} U_{d t-1}, E_{t-1} U_{c t}$ - $\phi_{c} \mathrm{U}_{c t-1}$. Let $\phi$ be a $2 \times 2$ diagonal matrix, $\Phi=\operatorname{dlag}\left(\phi_{c}, \phi_{d}\right)$. Also, let

(9) $D=D_{0}+b\left|\begin{array}{cc}0 & -\phi_{d} \\ 0 & 0\end{array}\right|, \quad \Omega_{u}-E\left(U_{t}-\Phi U_{t-1}\right)\left(U_{t}-\Phi U_{t-1}\right) \cdot-\operatorname{diag}\left(\sigma_{c}^{2}, \sigma_{d}^{2}\right)$.

The solution to (8) is

$$
\mathbf{Y}_{t}-\mathbf{I Y} \mathbf{Y}_{\mathrm{t}-1}+\mathbf{F \mathbf { U } _ { \mathrm { t } }},
$$

where II and $F$ are $2 \times 2$ matrices that depend on $b, D, \Phi, A_{0}$ and $A_{1}$. Since $U_{t}$ follows a vector $\operatorname{AR}(1)$ with coefficlent matrix $\Phi, F_{t}$ follows a vector $A R(1)$ with coefficient matrix $F \Phi F^{-1}: F U_{t}=\left(F \Phi F^{-1}\right) F U_{t-1}+F\left(U_{t}-\phi U_{t-1}\right)$. To obtain an equation with a serially uncorrelated disturbance, quasi-difference (10) to obtain

$$
Y_{t}-F \Phi F^{-1} Y_{t-1}-\pi Y_{t-1}-F \Phi F^{-1} I Y_{t-2}+V_{t}, V_{t}-F\left(U_{t}-\Phi U_{t-1}\right)
$$

The aim of this paper is to use (11) to determine how cost and demand shocks interact to determine inventorles, production and sales. This requires estimates of II, $\Omega, E V_{t} V_{t^{\prime}}, \Phi$ and $F$. Given $F \Phi F^{-1}$, the first two are easily obtained from (11) by IInear regressions; calculating $F \Phi F^{-1}$ entalls some work (see below and the append(x). Given F, $\Omega$, may be diagonalized by multiplying it by $F^{-1}$. One may then 
apply standard VAR techniques to compute Impulse response functions and variance decompositions.

A basic check on the plausibility of the results is the pattern of impulse responses. While complicated and perhaps counterintultive dynamics are possible (Blinder [1986a]), Intultion suggests that the Inftlal Impact of a cost shock will be to cause inventorles, production and sales to fall, with a negative long run impact as well when there are unit roots. One expects the initial impact of a demand shock to cause production and sales to rise, with the effect on inventories indeterminate: production smoothing will tend to make the effect negative, $g_{E S}>0$ in equation (2) will tend to make the effect positive (see also Blinder (1986a)). When there are unle roots $\left(\phi_{d}-\phi_{c}-1\right)$, the long run impact of a demand shock on production and sales is positive, on inventories indeterminate (again because of conflicting forces from production smoothing and $\mathrm{g}_{\mathrm{BS}}>0$ ).

This section closes with an overview of the procedure used to identify the shocks, and may be skipped without loss of continuity. The first step is to obtain an estimate of $F \Phi F^{-1}$, which is used construct the right and left hand side variables In (11). Estimation of $F \Phi F^{-1}$ when $\phi_{c}$ and $\phi_{d}$ are unknown is discussed in the appendix. Consider instead when $\phi_{c}$ and $\phi_{d}$ are imposed a priori. This was true, with $\phi_{d}-\phi_{c}-1$, for one of the specifications estimated below. Then $\Phi-F \Phi F^{-1}-1$, the shocks follow uncorrelated random walks, and equation (11) is just $\Delta Y_{t}-\Pi \Delta Y_{t-1}+V_{t}$. Upon defining $\left(v_{1 t}, v_{2 t}\right)^{\prime}-v_{t}$, this may be written out in scalars as

$$
\begin{aligned}
& \Delta H_{t}=\pi_{11} \Delta H_{t-1}+\pi_{12} \Delta Q_{t-1}+v_{1 t}, \\
& \Delta Q_{t}=\pi_{21} \Delta H_{t-1}+\pi_{22} \Delta Q_{t-1}+v_{2 t} .
\end{aligned}
$$

Given a value of the discount rate $b$, the four $\beta_{\mathfrak{1}}(1>0)$ defined in equation (8) can be computed from the OLS estimates of the four $\pi_{1 j}$ 's. The estimates of the $\beta_{1}$ can 
then be used to compute the $g_{1 j}$, as well as $h, \sigma_{c}^{2}, \sigma_{d}^{2}$ and $F$. See the appendix for details. Note that the $g_{i j}$ are only identifled up to a normalization, as are $h$, $\Omega_{u}$ and F. (This is apparent in (6) and (7): doubling all the $g_{1 j}$ terms except $g_{B S}$ leaves the flrst order conditlons unchanged, apart from a rescaling of the disturbances.) The normalization chosen was $\beta_{0}-1$. Varlance decompositions, and impulse responses to a one standard deviation shock, however, are Invariant to cholce of normalization."

It should be noted that whether or not $\Phi$ is known a prlorl this is not the usual procedure for orthogonalizing vector autoregressive residuals (e.g.. Haltiwanger and Maccini [1987]), and 1ssues such as sensitivity of results to orderings of varlables are not relevant. The baslc algebralc reason for this is that the three unknowns $h, \sigma_{c}^{2}$ and $\sigma_{d}^{2}$ are determined uniquely by the three unknowns in $\Omega_{s}$.

\section{Empirical Results}

\section{A. Data and Estimation Technique}

The data were real (1982 dollars), quarterly, seasonally adjusted, and expressed at annual rates, 1947:1 to 1986:4. F1gures for GNP, final sales (demand) and inventory investment were obtained from CITIBASE files GNP82, GNS82 and GVB2. The Implied serles for inventorles was obtalned by setting the 1982:1 figure to match the corresponding entry in the CITIBASE file for real inventorles, GL82, and then using the series for 1mventory investment (GVB2) to compute the level in other quarcers.

The first step in the emplrical work was to model deterministic and stochastic trends. Regresstons of $\log$ levels of the data on a constant and time trend yielded estimated growth rates of 0.786 per cent per quarter for inventories, 0.828 percent for production; when inventorles and GNP were constrained to have a common 
deterministic growth rate, the figure was 0.807 percent per quarter. This suggested that it is reasonable to model the two variables as having a common deterministic trend, and, indeed, neither asymptotic nor Monte Carlo tests could reject the null of a common deterministic trend. Details on these tests, as well as on the consistency of geometric growth with the model, are in the additional appendix available on request. The data used in all the estimation below therefore are data "scaled" by this common deterministic trend, 1.e., the 1982 data just described divided by $(1.00807)^{t}$. The mean values for scaled inventories, GNP and sales were $1,017,1,106$ and 1,099 billion 1982 dollars. See Figure I for a plot of the scaled data.

All the inference reported below is conditional on the estimated growth rate of 0.807 percent per quarter and, except for the results in Tables I and II below, on an imposed discount rate b-0.98 as well. Related work (West [1986]) and some tests described in a footnote suggest that the empirical results are not likely to be sensitive to even large errors in the estimate of this deterministic trend, or to the exact choice of discount rate. ${ }^{3}$

The Said and Dickey [1984] test for a unit root in the scaled data does not reject the null of a unit root in either GNP or inventories at even the ten percent level, for elther 4 lags ( $t$-statistic for $\mathrm{H}_{0}$ : coefficient on lagged dependent variable-1 is -1.96 for GNP, -1.20 for inventories) or 12 lags (t-statistic = -1.62 for GNP, -1.16 for inventories), using either the asymptotic or Monte Carlo levels in Schwert [1987]. This suggested the importance of a differenced $\left(\phi_{c}=\phi_{d}-1\right)$ specification. On the other hand, extreme serial correlation of GNP and inventories is consistent with a stationary model as well, with the persistence coming from $\phi_{c}$ and $\phi_{d}$ less than but near unity. This suggests the plausibility of an undifferenced specification as well. A cointegrated specification seemed of secondary interest because the null of no cointegration of GNP and inventories was not rejected at even 
the ten per cent level using the Engle and Granger [1987] CRDW test, when either GNP was regressed on inventories (Durbin-Watson - 0.070) or inventories on GNP (Durbin Watson -0.042 ).

This suggests the importance of two of the specifications estimated: a differenced one, with $\phi_{c}-\phi_{d}-1$ 1mposed, and a quas1-differenced one, where $\phi_{c}-0.969$, $\phi_{d}-0.997$ was estimated as described in the appendix. In this stationary

specification, demand disturbances were overwhelmingly dominant at distant horizons, for GNP (see the discussion of Table $v$ below). To check whether this result followed simply because $\phi_{d}$ was very near one, and slightly larger than $\phi_{c}$, a third and final specification estinated $\phi_{d}$ and $\phi_{c}$ subject to the constraint that $\phi_{c}-\phi_{d}$. The maximum 11kelihood estimate was $\phi_{c}-\phi_{d}-0.949$. See Table I for a summary of the serial correlation parameters for the three specifications, as well as the left hand side variables used in the regression estimates of (11).

In all three specifications, confidence intervals for various estimates were bootstrapped (Efron [1982], Freedman [1984], Runkle (1987]), us Ing one thousand repetitions." For each of the one thousand repetitions: (a)a time series of $Y_{t}$ was generated recursively using the estimated II and $F \Phi F^{-1}$, and sampling the estimated residuals with replacement; (b)equation (11) was reestimated (holding FoF-1 fixed), to get another II. Inference was thus conditional on the estimated or imposed serial correlation matrix F\$F ${ }^{-1}$ (and, as noted above, on the value of the discount rate $b$ and the estimated growth rate).

Impulse responses and varlance decompositions over varlous fintte horizons were calculated in the standard way, using the RATS computer program. The results also report variance decompositions at an infinite horizon, computed simply as the limit of the finte horizon variance decompositions.

A specialization of the model that involves a simple form of costs has simple implications for the relative varlabilities of GNP and final sales. Suppose in 
particular that $h-g_{10}-\mathrm{g}_{B S}-0$, so that $C_{t}-B_{00} Q_{t}{ }^{2}+B_{0 B} H_{t}{ }^{2}+2 Q_{t} U_{c t}$. Assume tentatively that all varlables have a zero unconditional mean. Then in a statlonary environment, (a) In the presence of demand shocks only $\left(U_{c t}=0\right), 0 \leq E\left(S_{t}{ }^{2}-Q_{t}{ }^{2}\right)=E S_{t}{ }^{2}$ $8 Q_{t}{ }^{2}-\operatorname{var}(S)-\operatorname{var}(Q)$, or $\operatorname{var}(Q) / \operatorname{var}(S) \leq 1$ (West [1986]); (b) in the presence of cost shocks only $\left(U_{d t}=0\right), \operatorname{var}(Q) / \operatorname{var}(S) \geq 1$ (see the additional appendix available on request).

In the presence of unit roots, variances do not exist, but analogous inequalities nonetheless hold (West [1987]). Since $S_{t}-Q_{t}-\Delta H_{t}, S_{t}{ }^{2}-Q_{t}{ }^{2}=-2 Q_{t} \Delta H_{t}+$ $\Delta H_{t}{ }^{2}$. Under falrly general conditions--including in particular when $\left(\Delta H_{t}, \Delta Q_{t}\right)$ follows a vector autoregression, as in the present paper--EQ $\Delta H_{t}=E\left[\left(\Delta Q_{t}+\Delta Q_{t-1}+\right.\right.$ ... $\left.) \Delta H_{t}\right]-E\left[\left(\Sigma_{y-0} \Delta Q_{t-j}\right) \Delta H_{t}\right]$ exists (1s finlte). The simplifled model defined in the previous paragraph then implies (a) in the presence of demand shocks only $\left(U_{c t}=0\right), 0$ $\leq E\left(S_{t}{ }^{2}-Q_{t}{ }^{2}\right)$, (b) In the presence of cost shocks only $\left(U_{d t}-0\right), 0 \geq E\left(S_{t}{ }^{2}-Q_{t}{ }^{2}\right)$.

That the data do not have zero means, and are first scaled by $g^{t}$, is irrelevant for the stationary speciflcation but introduces some minor complications for the unt root specification. As explained in the additional appendix available on request, it is necessary to examine not $-2 \operatorname{cov}\left(Q_{t}, \Delta H_{t}\right)+\operatorname{var}\left(\Delta H_{t}\right)$ but $-2 \operatorname{cov}\left(Q_{t}, \Delta H_{t}\right)+$ $g^{-2} \operatorname{var}\left(\Delta H_{t}\right)$. This was calculated in a straightforward fashion from the $\left(\Delta H_{t}, \Delta Q_{t}\right)$ autoregression, and is reported in the Table IV entrles for $E\left(S_{t}{ }^{2}-Q_{t}{ }^{2}\right)$.

\section{B. Emplatcal Results}

Estimates of the reduced form, of cost and demand parameters, of impulse response functions, of production and sales varlability, and of variance decompositions w11l be discussed in turn. Table II has estimates of the reduced form (10), where $\mathbb{I}-\left[\pi_{1 j}\right]$. (Constant terms were Included in all the regressions, but are not reported to conserve space.) Given how close are the values of $\phi_{c}$ and $\phi_{d}$, the reduced from esimates are of course quite similar (columns (2) to (5)). 
The results of three diagnostic tests are reported in columns (6) to (8). The Q statistics in columns (6) and (7) cannot refect the null of no serial correlation in the residuals at the 5 per cent level, though they do reject at the 10 percent level for the inventory equation all three specifications. Colum (8) reports maximum likelihood tests of the null of a lag length of one versus a lag length of two (after differencing or quasi-differencing by $\mathbf{F} \Phi F^{-1}$ ). These reject the null of a $1 \mathrm{ag}$ length of one quite strongly. For the stationary specifications, tests of an unrestricted lag length of two, in levels, versus the restricted second order VAR implied by (11) also reject the null at the .05 level (not reported in the Table)

The rejection of the overidentifying restrictions reported in column (8) suggests that this model is too simple to fully characterize the data.

Qualitatively similar resules obtain, however, when a more complicated model that implies a longer length VAR is used (see section $C$ below), since the present model is simpler to interpret, and since the parameter estimates and impulse response functions are for the most part quite plausible (see below), I will focus on this simple model.

Cost and demand parameters are reported in Table III, with the normalization as stated in the Table. Most parameters are correctly signed. The demand curve slope $g_{0 s}$, the inventory cost $g_{08}$ and the cost of adjustment $g_{10}$ are all fairly precisely estimated, and are consistent with those for the automobile industry (Blanchard [1983]) and for two digle nondurables manufacturers (West [1986]). The target level parameter ges is, however, incorrectly signed, although the 95 percent confidence interval is so large that it includes values such as .4 and .7 that are consistent with Blanchard [1983], Ramey [1988] and West [1986]. I therefore interpret this as a noisy and imprecise sample estimate of a population parameter that is positive (though perhaps smal1). Particularly interesting are the estimates of the quadratic production cost $\mathrm{B}_{00}$. As in Blanchard [1983], this cost is insignificanty 
different from zero and constant returns to scale cannot be rejected. As in Ramey [1988], however, the point estimates are negative, implying a tendency to bunch production.

Figures II and III plot the response to one standard deviation cost and demand shocks for the $\phi_{c}-\phi_{d}=0.949$ specification. Figures IV and $V$ do the same for $\phi_{c}=\phi_{d}-1.0$. (To conserve space, plots for $\phi_{c}=0.969, \phi_{d}=0.997$ are not presented, but any differences from $\phi_{\mathrm{g}}-\phi_{\mathrm{d}}-0.949$ are noted below.) The signs of the shocks are as in equations (1) and (2): a positive cost shock raises costs, a positive demand shock raises demand. The units on the vertical axis are billions of 1982 dollars. Note that the vertical scale in Figure III is slightly more compact than in the other three figures, and that the horizontal scales are different for the $\phi_{c}-\phi_{d}=0.949$ and $\phi_{c}-\phi_{d}=1.0$ specifications.

In response to a positive stationary cost shock (Figure II), GNP, inventories and final sales all fall initially, then rise back to the initial steady state. The smoothing role of inventories is illustrated by the sharper initial fall of GNP than demand, in response to the increase in costs; without inventories, this sharper fall would not be possible. The smoothing pattem appears to make GNP more variable than sales, as is expected in simplified versions of the model in the presence of cost shocks alone.

The GNP and sales responses to a stationary demand shock, in Figure III, are familiar hump-shaped ones. As in Blanchard and Quah [1988], the peak response occurs at about four quarters. Inventories are initially drawn down, thereby buffering GNP from the shock. They are then built up, accumulating above the steady state level before falling back down. The pattem is similar to Haltiwanger and Maccini's [1987] estimates of the response of finished goods inventories to new orders shocks. The smoothing by inventories appears to make GNP more variable than demand. This is inconsistent with the standard production smoothing model with goo 
positive, but is unsurprising given that the estimated $g_{00}$ is negative."

In response to a positive random walk cost shock (Figure IV), inventories, demand and GNP all fall. Once again, inventories perform their smoothing role, allowing demand to fall less than GNP. The decline in both inventories and final sales is almost monotonic; GNP displays a hump shape (as in Blanchard and Quah (1988) and King et al. (1987)). The new steady state is essentially obtained in about two years, again as in Blanchard and Quah [1988] and King et al. [1987]. (The similarity of the steady state changes in final sales and GNP results because inventory investment (the first difference of inventories) is assumed stationary.)

In response to a positive random walk demand shock (Figure $V$ ), inventories are drawn down, demand and GNP rise. Some smoothing is apparent initially, al though GNP quickly rises past demand. Inventories show a hump shape; the return back towards the initial level again suggests a target level. The steady state is again reached in about two years.

Table IV reports the relative variability of GNP and final sales, using the $\phi_{c}=\phi_{d}=0.949$ and $\phi_{c}=\phi_{d}-1$ specifications. As is well known (Blinder [1981]), the variance of GNP exceeds that of finai sales (1ine 1, column 2). The appropriate inequality holds as well when unit roots are assumed present ( 1 ine 1, column 1). The impression from the Figures that GNP is more variables than sales, in response to either cost or demand shocks, is borne out by the relevant point estimates (lines 2 and 3 ), though the excess variability is statistically insignificant at the 95 percent level when there are demand shocks only (line 2).

Table IV suggests an explanation of the seeming contradiction between the Blinder [1982] version of the production smoothing model and the fact that GNP is more variable than final sales. The bulk of the explanation is that cost shocks are important. But even in the absence of cost shocks, GNP would possibly continue to be more variable. This excess variability appears to be attributable at least in 
part to a small tendency to bunch production (1.e., to the small negative value of $\left.g_{0 \infty}\right)$ : If the Table IV figures are recalculated for the $\phi_{\mathrm{c}}=\phi_{\mathrm{d}}-1.0$ specification under the counterfactual assumption that $g_{00}-0$ (constant rather than increasing returns to scale), with all other parameters held constant, the entry in line (2) for just demand shocks falls to 0.994 .

Table $\mathrm{V}$ has variance decompositions. In all three specifications, the variance of inventories is largely attributable to cost disturbances. This is especially true at relatively long horizons. The point estimates suggest that over 90 per cent of the variance is attributable to cost shocks at horizons of 4 quarters or more, the confidence intervals that it is unlikely that less than half the variance is due to cost shocks. This dominance of cost shocks is consistent with the marked procyclicality of inventory stocks (see Figure I), and is perhaps unsurprising given that the estimates of the accelerator parameter gas were negative.

All three specifications attribute to cost shocks about 40 to 60 per cent of the variability of GNP at horizons of about 20 quarters. At longer horizons, however, there are marked differences between the two specifications that impose $\phi_{c}=\phi_{d}$ (columns (1) and (2)) and the one that does not (column (3)). When $\phi_{d}-\phi_{c}$, the infinite horizon figure is still about 40 to 60 per cent, but for $\phi_{c}-0.967$, $\phi_{d}-0.996$, the figure is about only a little above 10 per cent. A comparison of columns (2) and (3) Indicate that this is an artifact of the slighty higher point estimate of $\phi_{d}$ : if $\phi_{d}=1, \phi_{c}<1$, the contribution of cost shocks at an infinite horizon would of course be zero. Here, Instead, $\phi_{d}$ is slightly less than one, so the contribution of cost shocks at that horizon is not exactly zero. ${ }^{10}$ I am therefore inclined to downplay the infinite horizon decompositions in column (3). In this connection, the reader should recall that the confidence intervals are conditional on the estimates of $\phi_{c}$ and $\phi_{d}$, so the upper bound of 34.9 in the infinite horizon confidence interval in column (3) probably is consistent with a 
point estimate in the 40 to 60 range.

This 40 to 60 per cent range is bracketed by the somewhat higher estimates in Blanchard and Quah [1988] and King et al, [1987], and the somewhat lower estimates in Blanchard and Watson [1986] and Falr [1988]. ${ }^{11}$ A possible reconclliation with the two papers that find higher estimates is that permanent shocks, tentatively linked in those papers to cost rather than demand, are in fact partly demand related: in the present context, at least, nothing in the model or results argues for allowing for cost but not demand shocks to be permanent.

A possible reconciliation with the three papers that find a smaller role for costs is suggested by the only one of the papers that has an inventory equation, Falr [1988]. Falr uses a standard flexible accelerator/production smoothing model. Desired inventories are proportional co sales; actual inventorfes adfust only partially toward the desired level (Falr (1984, ppl31-132)). In Fair [1988], the shock to the inventory equation is interpreted as one of the components of the aggregate demand shock. In the present paper, however, the shock to the inventory equation in both (8) and (10) depends on cost as well as demand. Inventory investment therefore responds to cost shocks. The same plausibly applies to other types of business investment. Insofar as the shocks to the aggregate demand curve in Blanchard and Watson [1986] are due to business Investment, some of the GNP varlabllity that those papers attrlbute to aggregate demand shocks might more properly be attributed to aggregate cost shocks. In any case, whether or not I am correct in arguing that shocks to investment equations plausibly reflect cost as well as demand, my argument does suggest why I find a more important role for cost shocks than do and Blanchard and Watson [1986] and Falr [1988]. Whether this argument is persuasive of course will require further research.

To return to Table $v$ : Cost shocks are less important for GNP as the forecast horizon increases. This pattern held quite rigidly. Although not reported in Table 
v, the fraction of GNP variability attributable to cost shocks declined monotonically as the horizon increased. Evidently, demand shocks are estimated to have increasing real effects for GNP, with inventories serving as a buffer. This is 11lustrated in the 1mpulse responses. In both specifications, GNP responses to cost shocks show an earlier peak and a quicker approach to the steady state.

The decreasing Importance of demand shocks is consistent with Maccini and Haltiwanger [1987], who report an analogous tendency for shocks to new orders to account for an increasing fraction of the variance of manufacturing inventories as the forecast horizon increases. The contradictory Blanchard and Quah [1988] and King et al. [1987] result that cost shocks are Increasingly important as the horizon Increases again potentially can be reconciled with Table $\mathrm{V}$ if permanent disturbances are demand as well as cost related.

Finally, fluctuations in final sales appear to be attributable in roughiy equal shares to cost and demand shocks. (I again discount the results in column (3), for the reasons given above.) There does not appear to be a marked tendency for cost shocks to be particularly important at any particular horizon. (Once again, for the differenced specification, the similarity of the infinite horizon decompositions for GNP and sales results because inventory investment is stationary.)

\section{Additional Empirical Results}

As a check on the preceding results, two additional sets of estimates were obtained. For simplicity, I imposed $\phi_{c}=\phi_{d}-1$ in both, and did not compute any confidence intervals. The first set of estimates was already mentioned in the discussion of diagnostic tests, and used a more complicated model that implied a longer length VAR. Equation (2)'s cost function was expanded to:

(13) $C_{t}-g_{0 Q} Q_{t}^{2}+g_{1 Q} \Delta Q_{t}^{2}+g_{0 B}\left(H_{t-1}-g_{B S} S_{t}\right)^{2}+2 U_{c t}\left(h H_{t}+Q_{t}\right)+$

$$
g_{1 B} \Delta H_{t}^{2}+g_{1 B Q} \Delta H_{t} \Delta Q_{t}+g_{2 I} \Delta^{2} H_{t}^{2}+g_{2 O} \Delta Q_{t}^{2} \text {. }
$$


The four additional terms are suggested by Eichenbaum [1984]. With $\phi_{c}=\phi_{d}-1$, this can be shown to lead to an exactly identified second order VAR in $\left(\Delta Q_{t}, \Delta H_{t}\right)$. Diagnostic tests on the OLS estimates of this second order VAR: For the $\Delta H_{t}$ equation, $Q(36)$ for the residual was 32.81 ( $p$-value - 0.62); for the $\Delta Q_{t}$ equation, $Q(36)-28.37$ ( $p$-value - 0.82); $\chi^{2}(4)$ for lags-2 against lags-3 (second order against third order VAR) yields 4.33 (p-value-0.36).

Point estimates for the $g$. are given in Table VIA. Of the five parameters present in the model used above, four fall within the 95 percent confidence incervals in line 1 of Table III (the exception is $g_{10}$, which is a little larger than one would expect from the Table III confidence interval). Most of the four additional parameters are small relative to the original parameters, with three of the four ( $g_{20}, g_{18}, g_{2 H}$ ) having negative signs. The interpretation of these negative signs is unclear. Perhaps this suggests a tendency to bunch inventory holdings as well as production. The entries corresponding to the "on line in Table $V$ are reported in Table VIB. As may be seen, they are consistent with the Table $V$ entries.

I conclude that even though the model in section B was, as usual, rejected by tests of overidentifying restrictions, substantively different results are unlikely to be produced by extensions to models that are complicated and more difficult to interpret, but unrejected.

A second set of additional estimates considered the implications of the imprecise estimates of the accelerator parameter gas. In this set, gas was fixed at 0.68 Instead of its estimated value of $-.04 ; .68$ is the upper bound of the 95 percent confidence interval in line (1) of Table III, and is consistent with the estimates of some earlier studies (Blanchard [1983], West [1986]). Holding the other $g$.. parameters fixed at the values reported in Table III, I then solved for 
the reduced form and used this in all subsequent calculations.

One would expect the higher value of $g_{a s}$ to lead to a less fmportant role for cost shocks, since more of the procyclical movement of inventorles will be attributed to movements in demand. Indeed, with the other $\mathrm{g}$.. parameters held fixed at the values reported in Table III, the implied Infinite horizon fraction of the variance of inventorles, GNP and sales due to cost shocks falls, to 66, 9 and 9 . See Table VII. The estimates in Table V, then, are sufficiently imprecise that fixing gas a plausible value that is rather different from its estimated value results in a varlance decomposition that is rather different, and more consistent with some earlier studies (e.g., Fair [1988,p232] who finds that supply shocks account for 7 percent of the variance of the eight quarter ahead forecast error in GNP) .12

\section{Conclusions}

Fluctuations in aggregate inventories in the postwar $U . S$. appear to be due more to fluctuations in cost than in demand. Despite some long standing difficulties in linking movements in inventories to those in costs (a recente example is Miron and Zeldes (1987]), the implication is that future inventory research should emphasize the role of costs. Fluctuations in GNP appear to be due in roughly equal proportions to fluctuations in cost and demand. The point estimates are, however, noisy. With a different, and plausible, value for the parameter that determines a target inventory-sales ratio, cost shocks are less important than demand shocks for GNP fluctuations. 


\section{Footnotes}

1. An exception is production to order manufacturing, when demand is measured by orders rather than sales (West [1988]).

2. Readers who prefer the monopolist interpretation should note that under that interpretation the parameter estimate called $g_{0 s}$ is instead an estimate of $.5 g_{0 s}$. In a related context, Eichenbaum [1984] states that an oligopolistic structure results in an observationally equivalent equilibrium, provided individual firms follow symetric open loop Nash strategies.

3. Necessary conditions for $(8)$ and $(10)$ to be the optimal solution to the model include (1) $A_{0}$ is positive definite (the Legendre-Clebsch condition for optimality (Stenge1, 1986,p213]); (2) the two smaller of the four roots to $\left|b A_{1} \cdot z^{-1}+A_{0}+A_{1} z\right|-0$ are strictly less than $b^{-1 / 2}$ in modulus. These conditions are guaranteed to hold if $g_{09}, g_{09}, g_{0 s}, g_{10}>0$. See Hansen and Sargent [1981]. I thank Tryphon Kollintzas for clarifying this point.

4. Actually, impulse response functions are invariant only up to a sign change.

5. For the $\phi_{c}-\phi_{d}-1$ specification described below, I calculated the infinite horizon variance decompositions described in the next paragraph, for data scaled by $(1.012)^{t}-[1+(1.5) \times(.008)]^{t}$ and $(1.004)^{t}-[1+(.5) \times(.008)]^{t}$. None of these estimates were more than four percentage points different than the figures reported in Table $V$ below. See West [1986] on the insensitivity of results to exact choice of $b$.

6. For the differenced specification, asymptotic standard errors were also calculated for some of the parameter estimates, in a fashion similar to that described in West [1988]. The results were about the same.

7. While $\mathrm{g}_{\mathrm{gS}}<0$ is not sensible, this model still generates a positive level of inventories (see Schutte [1983]). In the underlying model that allows for deterministic growth in inventories and production, which is described in detail in the additional appendix available on request, the quadratic costs in (2) are 
interpreted as costs around a minimum point that grows over time. This growth can lead to positive inventory levels even if gas is negative (or, more plausibly, zero).

8. The estimated value of $g_{00}$ is small enough relative to the other parameters that the conditions noted in footnote 3 are met. It should be emphasized that the conditions in that footnote are necessary but not sufficient. James Hamilton has pointed out to me that these conditions therefore do not establish that the point estimates are consistent with (8) and (10) characterizing the optimal policy.

9. For $\phi_{c}-0.969, \phi_{d}-0.997$, the response to a cost shock is quite similar to that in Figure II, but the response to a demand is somewhat different from Figure III, in that (a)even after 80 quarters, no return to the steady state is obvious (this of course results since $\phi_{d}$ is so near unity), and (b)after initially falling, inventories rise up above the steady state before finally falling back towards the steady state.

10. The "ه" entry for $H_{t}$ in column 3 indicates that this argument does not yet apply to inventories with $\phi_{\mathrm{d}}-.996$; it would of course eventually apply for some $\phi_{d}$ arbitrarily near unity.

11. Fair [1988] only calculates decompositions up to elght quarters out; these, too, attribute a much lower figure to costs than does Table V.

12. In defense of the present paper, it should be noted that these estimates do not seem to be any less precise than those in Blanchard and Quah [1988] or King et al. [1987]. Incidentally, for the $\phi_{c}-\phi_{d}=1$ specification, plots of the eight quarter ahead forecast error in GNP (as in Blanchard and Watson [1986]) indicated that both the cost and demand shocks tended to be negative in contractions, positive in expansions, with no noticeable tendency for cycles to be demand or cost driven. When ges was fixed at .68 , the same plot indicated that all cycles were demand driven (including, perhaps implausibly, the 1973-75 recession). 
Appendix

This discusses ( 1 )how to calculate F (defined in equation (10)), given estimates of $F \Phi F^{-1}$ and $\Pi$; (2) how to estimate $F \Phi F^{-1}$ and $\Pi$.

(1) Tentatively ignore the scaling for growth discussed in the text. Inserting (10) led once into (8) ylelds

$$
\begin{aligned}
& \mathrm{bA}_{1} \cdot\left(\pi \mathrm{Y}_{\mathrm{t}}+\mathrm{F} \phi \mathrm{U}_{\mathrm{t}}\right)+\mathrm{A}_{0} \mathrm{Y}_{\mathrm{t}}+\mathrm{A}_{1} \mathrm{Y}_{\mathrm{t}-1}-\mathrm{DU}_{\mathrm{t}}=0 \rightarrow \\
& b_{1} \cdot\left[\Pi\left(\pi Y_{t-1}+F U_{t}\right)+F \Phi_{t}\right]+A_{0}\left(\pi Y_{t-1}+F U_{t}\right)+A_{1} Y_{t-1}-D U_{t}-0 \rightarrow \\
& \text { (A1) } \mathrm{bA}_{1} \cdot \mathrm{H}^{2}+\mathrm{A}_{0} \Pi+\mathrm{A}_{1}=0 \\
& \text { (A2) }\left[\mathrm{bA}_{1}^{\prime}\left(F \Phi F^{-1}+\Pi\right)+A_{0}\right] F=D \text {. }
\end{aligned}
$$

After estimating the reduced form (11), one uses the four equations in (AI) to Iinearly recover the four elements of $A_{0}$ and $A_{1}$. Given estimates of $A_{0}$ and $A_{1}$, one can calculate the three unknowns $h, \sigma_{c}^{2}$, and $\sigma^{2}$ from the three equations in $\left[b A_{1}^{\prime}\left(F \Phi F^{-1}+\Pi\right)+A_{0}\right] \Omega_{v}\left[b A_{1}^{\prime}\left(F F^{-1}+\Pi\right)+A_{0}\right]^{\prime}-D \Omega_{q} D^{\prime}$. (An estimate of $\Omega_{v}$ is avallable from the covarlance matrix of the reduced form residuals.) One then calculates F $\left[\mathrm{bA}_{1}{ }^{\prime}\left(F \Phi F^{-1}+I\right)+A_{0}\right]^{-1} D$

As stated in the text, the data were scaled by a growth rate of $(1.00807)^{t}=g^{t}$ prior to estimation of (II). The model that allows such growth (described in detail In the additional appendix avaflable on request) implies that the first order condition (10) should be written

$$
E_{t}\left(b g A_{1}^{\prime} Y_{t+1}+A_{0} Y_{t}+B^{-1} A_{1} Y_{t-1}+D U_{t}\right)-0
$$

where $D-D_{0}+b g D_{1}, D_{0}$ and $D_{1}$ defined below equation ( 8 ). The calculations just described are then modifled in a straightforward fashion.

(2) When $\phi_{c}-\phi_{d}-\phi$ for some scalar $\phi, F F^{-1}-\phi I$, and it is straightforward to estimate $\phi$ 
and II subject to the restriction that $Y_{t}-\left(\phi I+\pi Y_{t-1}\right)-\phi \Pi Y_{t-2}+V_{t}$ for some scalar $\phi$. Then $F \Phi F^{-1}-\phi I$ and one proceeds as above. When $\phi_{c} f_{d}, \max i m u m$ likelihood is very cumbersome. (The constraint is not only nonlinear but involves both the regression parameters and the variance-covariance matrix.) The following procedure, which yields consistent though not efficient estimates, was therefore used instead:

(a) OLS was used to estimate the second order VAR $Y_{t}-\Pi_{1} Y_{t-1}+\Pi_{2} Y_{t-2}+V_{t}$.

(b) The matrix lag polynomial $I-\Pi_{1} L-\Pi_{2} L^{2}$ must be factored as $\left(I-F \Phi F^{-1} L\right)(I-\Pi L)$. For given $\Pi_{1}$ and $\Pi_{2}$, there may be zero, two or four real factorlzations. (Analogy: if $F \Phi F^{-1}, \Pi, \Pi_{1}$ and $\Pi_{2}$ were all scalars, there would be zero or two factorizations: zero if both roots to $1-\Pi_{1} L-\Pi_{2} L^{2}$ are complex, two if the roots are real. In the latter case one obtains two factorizations by assigning first one and then the other root to the serial correlation parameter $F \Phi F^{-1}$.) For the $\Pi_{1}$ and $\Pi_{2}$ actually estimated, there happened to be two real factorizations.

(c) Let $P-F \Phi F^{-1}$. For each factorization (each $P$ and $I$ ): (1) Compute $A_{0}$ and $A_{1}$ as described above. (i1) with some manipulation, (A2) implies that $D$ - $\left[b A_{1}{ }^{\prime}(P+\Pi)+A_{0}\right] P\left[b A_{1}{ }^{\prime}(P+\Pi)+A_{0}\right]^{-1} D$. Imposing that $\Phi$ is diagonal allows one to solve for $\phi_{d}$. Given $h$ (computed as described above), one can also use this to compute $\phi_{c}$. This yields and $D$. (iif) Compute $F$ as above, $F-\left[b A_{1}{ }^{\prime}(P+I)+A_{0}\right]^{-1} D$. (iv)Compute F $\Phi F^{-1}$ using the diagonal produced in step (11). Call this matrix $\mathrm{P}^{*}$. (v) The implied restricted VAR is $Y_{t}=(P *+\Pi) Y_{t-1}-P * \Pi Y_{t-2}+V_{t}$. Compute the likelihood (the log determinant of the variance covariance matrix of $V_{t}$ ).

(d) Select the factorization that yields the highest likelihood. This $P^{*}$ is what is reported as $F \Phi F^{-1}$ in Table $I$.

Estimation of the restricted model described in step (c), part ( $v$ ) may be done linearly, by defining left and right hand side variables that are appropriate transformations of current and lagged $H_{t}$ and $Q_{t}$.

University of wisconsin 
- Additional appendix, pl--

\section{Additional Appendix}

This appendix contains additional details on the empirical work that were omitted from the main body of the paper to save space. There are eight items:

I. Growth

II. Production versus sales variability

III. Tests for a common deterministic trend in $Q$ and $H$

IV. Estimation of infinite horizon variance decompositions

V. Regressions to scale data

VI. Estimates of the $\beta_{1}$

VII. Asymptotic standard errors for the $g_{1 j}$

VIII. Asymptotic standard errors for the $\pi_{1 j}, \phi_{c}-\phi_{d}-1$, both scaled and unscaled data

IX. Plots of impulse response functions for $\phi_{c}-.969, \phi_{d}=.997$. 


\section{Growth}

As noted in the text, exactly the same first order conditions, and, therefore, exactly the same reduced form, is delfvered by the observationally equivalent model in which the economy maximizes the excess of consumers surplus $W_{t} *$ over production costs,
(A3) $\max 1$ Im $T-\infty E_{0} \Sigma_{t=0}^{T} b^{t}\left(W_{t} *-C_{t}\right)$
s.t. $Q_{t}=S_{t}+\Delta H_{t}$.

where in the model in the paper $W_{t} *--g_{0 S} S_{t}{ }^{2}+2 U_{d t} S_{t}$. It is algebraically convenfent to work with the (A3) statement of the model. Let $h_{t}, q_{t}, s_{t}, u_{d t}$, and $u_{c t}$ be the original data and shocks in levels, with $H_{t}, Q_{t}, s_{t}, U_{d t}$, and $\mathrm{U}_{\mathrm{et}}$ the scaled data $\left(\mathrm{e} . \mathrm{g}, \mathrm{H}_{\mathrm{t}}-\mathrm{h}_{\mathrm{t}} / \mathrm{g}^{\mathrm{t}}\right)$. Let $\mathrm{W}_{\mathrm{t}} *-\mathrm{C}_{t}$ be

$$
\text { (A4) } \begin{aligned}
k_{t}- & g_{0 S} s_{t}^{2}-2 m_{0 S t} s_{t}+2 u_{d t} s_{t} \\
& -2 g_{0 B t}\left(h_{t}-m_{0 B t}-g_{B S} E_{t} s_{t+1}\right)-2 g_{0 Q t}\left(q_{t}-m_{0 Q t}\right)-2 g_{1 Q t}\left(\Delta q_{t}-m_{1 Q t}\right) \\
& -g_{08}\left(h_{t-1}-m_{0 B t}-g_{B S} s_{t}\right)^{2}-g_{0 Q}\left(q_{t}-m_{0 Q t}\right)^{2}-g_{1 Q}\left(\Delta q_{t}-m_{1 Q t}\right)^{2} \\
& -2\left(h \cdot h_{t}+q_{t}\right) u_{e t} .
\end{aligned}
$$

$k_{t}$ is a purely deterministic term that grows no faster than $\mathrm{g}^{2 t}$. The deterministic $m_{1 \mathrm{jt}}$ shift the bliss level and minimum costs points, $m_{1 \mathrm{jt}}=$ $g^{t} \mathbf{m}_{1, j 0}$. Also, $g_{1 j t}-g^{t} g_{1 j 0}$. Let $y_{t}-\left(h_{t}, q_{t}\right), u_{t}-\left(u_{c t}, u_{d t}\right)$. Substituting (A4) into (A3), using $q_{t}-s_{t}+\Delta h_{t}$ to substitute out for $s_{t}$, differentiating with respect to $q_{t}$ and $h_{t}$ and then dividing by two yields

$$
E_{t}\left(b A_{1}^{\prime} y_{t+1}+A_{0} y_{t}+A_{1} y_{t-1}+m_{t}-\left[D_{0} u_{t}+b D_{1} u_{t+1}\right]\right)=0
$$


--Additional appendix, p3--

where $m_{t}=\left(m_{g t}, m_{p t}\right)^{\prime}, A_{0}, A_{1}, D_{0}$ and $D_{1}$ are defined in equation $(8)$, and, e.g. ,

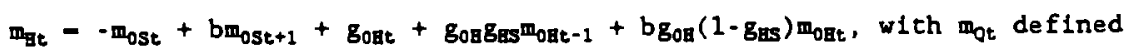
similarly. Dividing through by $g^{t}$ and rearranging yields

(A5) $E_{t}\left(b g A_{1}^{\prime} Y_{t+1}+A_{0} Y_{t}+g^{-1} A_{1} Y_{t-1}+M+D U_{t}\right)=0$,

where $D-D_{0}+b g D_{1}$ and $M-\left(M_{B}, M_{Q}\right)^{\prime}$, with, e.g., $M_{B}=-(1-b g) m_{O S O}+g_{0 B O}+g_{0 B} g_{H S} m_{O H O}+$ $\operatorname{bg}_{0 \mathrm{~B}}\left(1-\mathrm{g}_{\mathrm{BS}}\right) \mathrm{m}_{0 \mathrm{BO}}$. Equation (10) is a version of equation (A5) with the constant term and growth factor $g$ suppressed.

By mimicking the argument in Hansen and Sargent (1981), it can be established that $b A_{1} L^{-1}+A_{0}+A_{1} L=\left(C_{0}+b C_{1} L^{-1}\right)^{\prime}\left(C_{0}+C_{1} L\right)$, with $C_{0}+C_{1} L$ a stable polynomlal, $C_{0}+b C_{1} L^{-1}$ an unstable polynomlal. It follows that bg $A_{1} \cdot L^{-1}+A_{0}+g^{-1} A_{1} L-\left(C_{0}+b g C_{1} L^{-1}\right)^{\prime}\left(C_{0}+g^{-1} C_{1} L\right)$. Since $B \geq 1, C_{0}+g^{-1} C_{1} L$ is a stable polynomial. As long as bg<l, $C_{0}+b_{g} C_{1} L^{-1}$ is an unstable polynomial. The rule of solving stable roots backwards, unstable roots forwards leads to the solution in the text. 
- Additional appendix, p4--

\section{Production versus sales variability}

As in the previous section, let lower case letters denote the variables before scaling by $g^{t}$, uppercase letters denote scaled variables. Let $h_{t} / g^{t}=$ $H_{t}-E H+H_{t}, E H_{t}-0$, with similar notation for $Q_{t}$ and $S_{t}$. (This is not the same $H_{t}$ and $Q_{t}$ that appear in Tables I and II.)

In the stationary model, one can derive the inequality $\operatorname{var}(Q)<\operatorname{var}(S)$ in the presence of just demand shocks exactly as in West (1986). One compares the unconditional expectation of the infinite sum in equation (A3) under the optimal policy to that under the alternative policy that sets $h_{t}{ }^{A}-E h_{t}=$ $g^{t} E H, s_{t}^{A}-s_{t}, q_{t}^{A}-s_{t}+E \Delta h_{t}$. One can derive the inequality $\operatorname{var}(Q)>\operatorname{var}(S)$ in the presence of just cost shocks by performing the same comparison, this time with an alternative policy that sets $h_{t}{ }^{\wedge}-E h_{t}, s_{t}{ }^{A}-q_{t}-E \Delta h_{t}, q_{t}{ }^{A}=q_{t}$.

In a model with unit roots, if there is no deterministic trend to the data $(g-1)$, begin by noting that the period zero conditional expectation of the infinite sum in (A3) must be larger for the optimal policy than for any alternative. Consider the alternative that sets $h_{t}{ }^{\wedge}-E h_{t}=g^{t} E H, s_{t}{ }^{\wedge}-s_{t}$, $q_{t} \wedge=s_{t}+E \Delta h_{t}$, in the presence of just demand shocks. Quadratic inventory costs $\left(\mathrm{H}_{t}^{2}\right)$ are strictly greater in the optimal policy. So a necessary condition for optimality is that the conditional expectation of the difference between the optimal and alternative values of (A3), exclusive of such costs, is nonnegative. Taking unconditional expectations of this difference implies $0 \leq E\left(S_{t}{ }^{2}-Q_{t}{ }^{2}\right)$. The argument for $0 \geq E\left(S_{t}{ }^{2}-Q_{t}{ }^{2}\right)$ in the presence of just cost shocks is similar.

That $g>1$ introduces some slight complications. If, for example, $q_{t}{ }^{A}=s_{t}$ $+E \Delta h_{t}, Q_{t}{ }^{A}=q_{t}{ }^{A} / g^{t}-S_{t}+E H-g^{-1} E H=Q_{t}-H_{t}+g^{-1} H_{t-1}+E H-g^{-1} E H \rightarrow\left(Q_{t}{ }^{A}\right)^{2}$ - $\mathrm{Q}_{t}^{2}=-2 \mathrm{Q}_{t} \Delta \mathrm{H}_{\mathrm{t}}+\Delta \mathrm{H}_{\mathrm{t}}^{2}+\mathrm{Q}_{\mathrm{t}}\left(1-\mathrm{g}^{-1}\right) \mathrm{H}_{\mathrm{t}-1}$, and the last of these three terms does 
- -Additional appendix, p5--

not have a finite unconditional expectation. Considering instead the policy

$q_{t}^{A}=s_{t}+E \Delta h_{t}+[(g-1) / g]\left(h_{t}-E h_{t}\right)$, we find that $\left(Q_{t}^{A}\right)^{2}-Q_{t}^{2}--2 g^{-1} Q_{t} \Delta H_{t}+$ $\mathrm{g}^{-2} \Delta \mathrm{H}_{\mathrm{r}}{ }^{2}$, which does have a finite expectation. It is an estimate of $\operatorname{cov}\left(Q_{t}, \Delta H_{t}\right)+g^{-1} \operatorname{var}\left(\Delta H_{t}\right)$ that is reported in Table 3. 
- Additional appendix, p6--

II Tests for a common deterministic trend in $O$ and $H$

For the stationary specification, an asymptotic test of whether the two unconstrained growth rates of .786 and .828 percent are significantly

different from one another was performed. This did not reject the null of a common growth rate at conventional significance levels (t-statistic less than 1.43, using either fifth, tenth, or fifteenth order Newey and West (1987) corrections). For the nonstationary specification, a bootstrap test of the null of one deterministic and of the null of two stochastic trends was performed. The residuals for the AR(1) first difference specification were sampled with replacement, the scaled data were generated according to the estimated VAR parameters, and unscaled data were constructed using the estimated common growth rate of .807 percent. For each sample, I estimated and saved (a) the absolute value of the difference between the estimated growth rates of (i) inventories and (ii)GNP, and (b)the Durbin Watson of the regression of scaled inventories on scaled GNP, with an estimated common growth rate used for scaling.

Fewer than 60 percent of the estimates of the separate growth rates were less than $.042(-.828-.786)$ percent apart. The null of a common deterministic trend thus cannot be rejected. In addition, fewer than 50 percent of the Durbin-Watson statistics from the regression of scaled inventories on scaled GNP were smaller than .042 , the figure for the actual data. Thus, the null of two stochastic trends cannot be rejected. 
- Additional appendix, p7-.

\section{Estimation of infinite horizon variance decompositions}

For data assumed stationary these are just unconditional moments. calculated from the Yule-Walker equations. For differenced data these were calculated by computing 1 im $n-n^{-\infty} n^{-1} \operatorname{var}\left(Y_{t+n}-E_{t} Y_{t+n}\right)-$ $(I-I I)^{-1}\left(F \cap_{u} F^{\prime}\right)(I-I)^{-1}$, (easily established). This yields estimates of, say, $\theta_{1}$ and $\theta_{2}$, where 1 im $n-\rightarrow \infty n^{-1} \operatorname{var}\left(Q_{t+n} \cdot E_{t} Q_{t+n}\right)-\theta_{1} \sigma_{c}^{2}+\theta_{2} \sigma_{d}^{2}$. The infinite horizon fraction of the variance of $Q_{t}$ due to cost shocks was then computed as $\theta_{1} \sigma_{c}^{2} /\left(\theta_{1} \sigma_{c}^{2}+\theta_{2} \sigma_{d}^{2}\right)$ 
- -Additional appendix, p8--

\section{Regressions to scale daca}

A. The first regression 1 s that of $\log (\mathrm{H})$ on a constant and a time trend, the second that of $\log (Q)$ on a constant and a time trend, the third that of $\log (H)$ and $\log (Q)$ on constants and a time trend, constraining the coefficlent on the time trend but not the constant to be the same for both $\log (H)$ and $\log (Q)$.

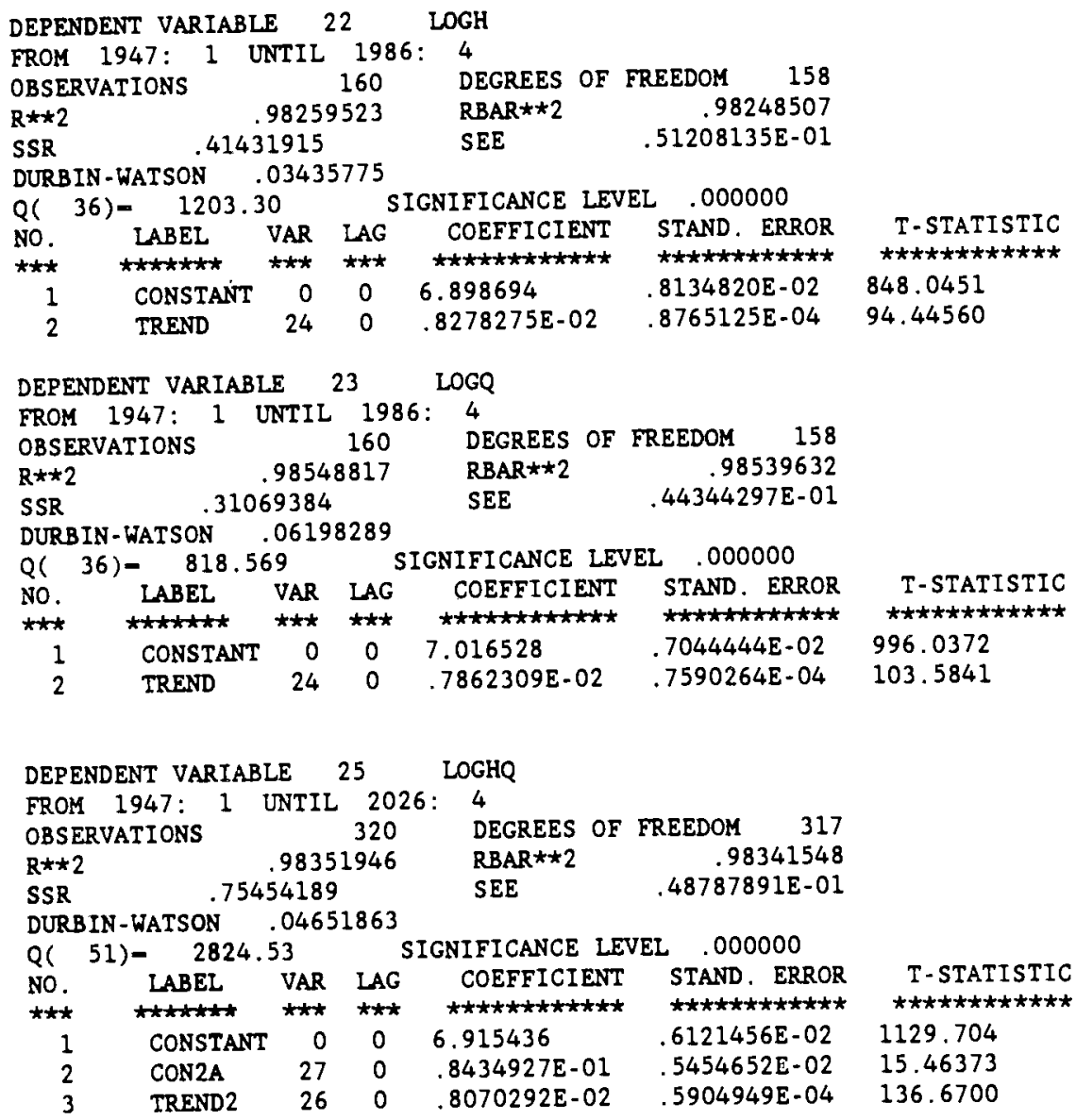


--Additional appendix, p9--

\section{Estimates of the $\theta_{1}$}

95 percent confidence intervals, from the bootstrap, are in parentheses.

$\begin{array}{lllll}\phi_{c}+\phi_{d} & B_{1} & B_{2} & B_{3} & B_{1}\end{array}$

$1.0,1.0 \quad-.39 \quad-.93 \quad-.34 \quad-.40$

$(-.68,-.15)(.41,1.52)(-.39,-.21)(-.63,-.18)$

$.949, .949(-.61,-.11)(.29,1.40)(-.42,-.25)(-.58,-.17)$

$.997, .969 \quad-.37 \quad 0.87 \quad-.35 \quad r 33$

$(-.66,-.13)(.30,1.47)(-.48,-.20)(-.61,-.13)$

\section{Asymptotic standard errors for the $g_{1 j}$}

$\begin{array}{llllll}\phi_{c}, \phi_{\mathrm{d}} & g_{00} & g_{0 S} & g_{0 \mathrm{~B}} & g_{\mathrm{BS}} & g_{10}\end{array}$

$\begin{array}{llllll}1.0,1.0 & -.072 & .392 & .145 & -.040 & .344 \\ & (.128) & (.152) & (.064) & (.352) & (.050)\end{array}$


- Additional appendix, plo--

VIII. Asymptotic standard errors for the $\pi_{1 j}, \phi_{c}=\phi_{d}-1$, both scaled and unscaled data

Scaled data:

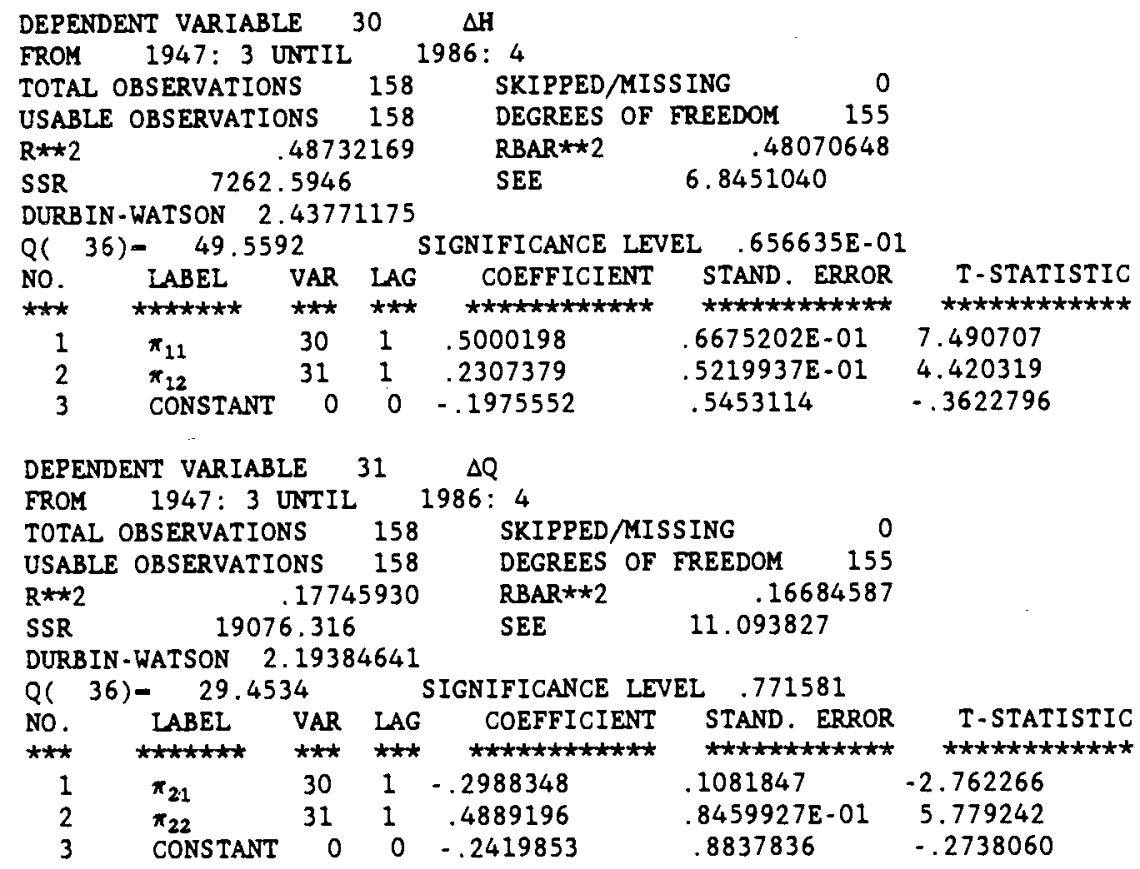


--Additional appendix, p1l..

Unscaled (raw) data:

DEPENDENT VARIABLE $30 \quad \triangle H$

FROM 1947: 3 UNTIL 1986: 4

TOTAL OBSERVATIONS 158 SKIPPED/MISSING

USABLE OBSERVATIONS 158 DEGREES OF FREEDOM 155

$\begin{array}{llll}R \star * 2 & .48683366 & \text { RBAR } \star 2 & .48021216\end{array}$

$\begin{array}{llll}\text { SSR } & 30186.405 & \text { SEE } & 13.955322\end{array}$

DURBIN-WATSON 2.38573786

Q( 36)- 45.0114 SIGNIFICANCE LEVEL .144211

\begin{tabular}{|c|c|c|c|c|c|c|}
\hline $\begin{array}{l}\text { No. } \\
\star \star \star\end{array}$ & $\underset{\star \pm \star \star \star \star \star \star \star}{\operatorname{LABEL}}$ & $\begin{array}{l}\text { VAR } \\
\star \star \star \star\end{array}$ & $\begin{array}{l}\text { LAG } \\
\star \star \star\end{array}$ & 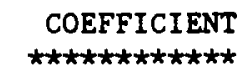 & 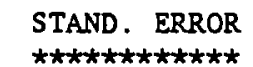 & $\begin{array}{r}\text { T-STATISTIC } \\
\star \star \star \star \star \star \star \star \star \star \star \star \star \star \star *\end{array}$ \\
\hline $\begin{array}{l}1 \\
2 \\
3\end{array}$ & $\begin{array}{l}\pi_{11} \\
\pi_{12}\end{array}$ & $\begin{array}{l}30 \\
31 \\
0\end{array}$ & $\begin{array}{l}1 \\
1 \\
0\end{array}$ & $\begin{array}{l}5329307 \\
.2232077 \\
3200179\end{array}$ & $\begin{array}{l}.6298521 \mathrm{E}-01 \\
.4883594 \mathrm{E}-01 \\
1471144\end{array}$ & $\begin{array}{l}8.461203 \\
4.570563 \\
2.175300\end{array}$ \\
\hline
\end{tabular}

DEPENDENT VARIABLE $31 \quad \triangle Q$

FROM 1947: 3 UNTIL 1986: 4

TOTAL OBSERVATIONS 158 SKIPPED/MISSING

USABLE OBSERVATIONS 158 DEGREES OF FREEDOM 155

$R \star \star 2$

.16822391

SSR

80816.213

RBAR $* * 2$

.15749132

DURBIN-WATSON 2.18309959

$Q(36)=46.2777$

SEE

22.834074

NO. LABEL VAR LAG COEFFICIENT STAND. ERROR T-STATISTIC

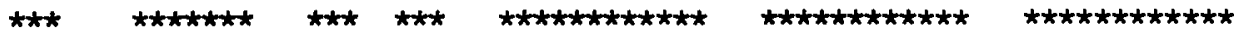

1

2

$\begin{array}{llll}\pi_{21} & 30 & 1 & -.3528995\end{array}$

$.1030581 \quad-3.424277$

$\begin{array}{llll}\pi_{22} & 31 & 1 & .4339241\end{array}$

$.7990668 \mathrm{E}-01 \quad 5.430386$

3 CONSTANT 0 0 14.74241

2.407125

6.124491 


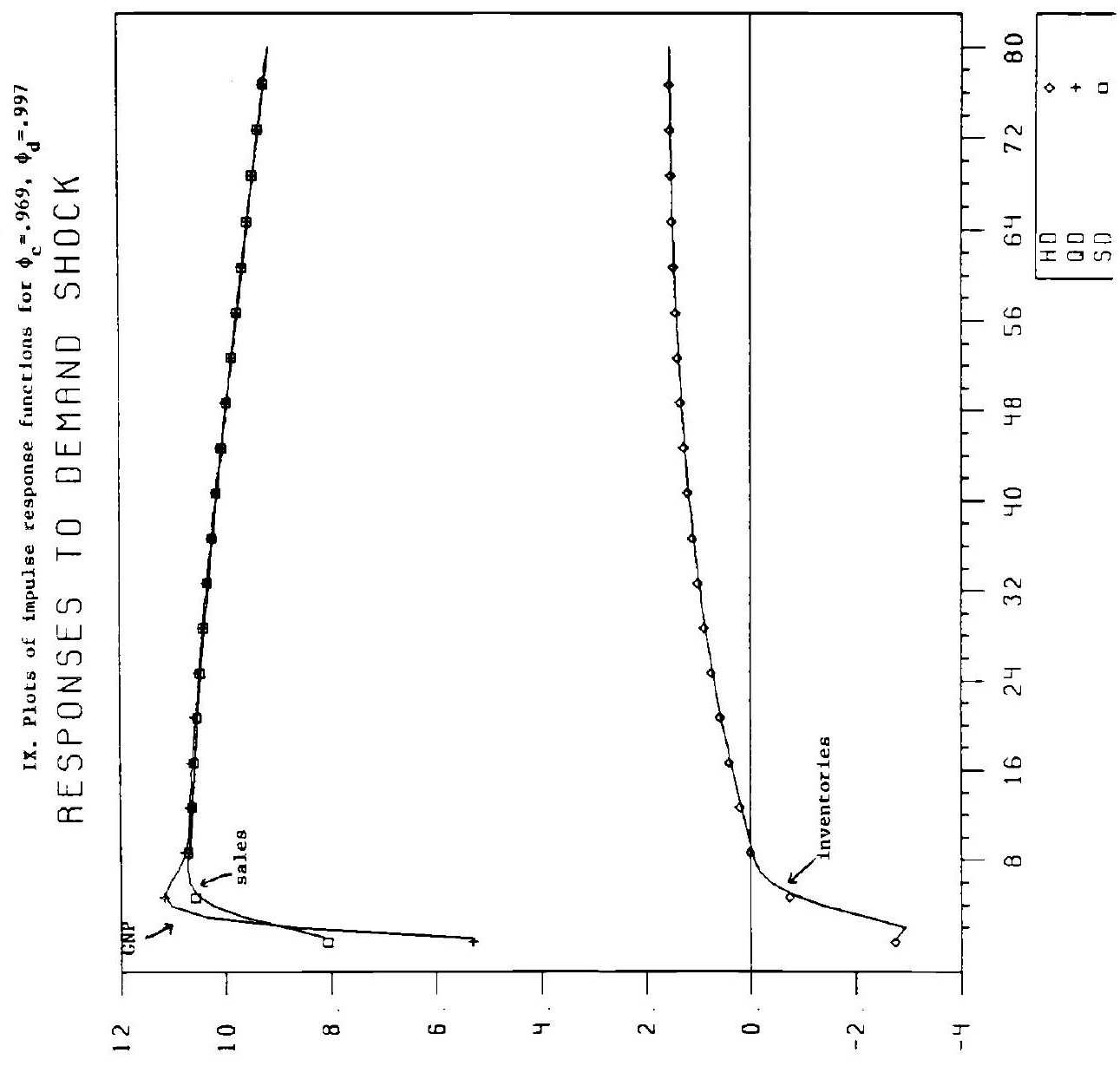




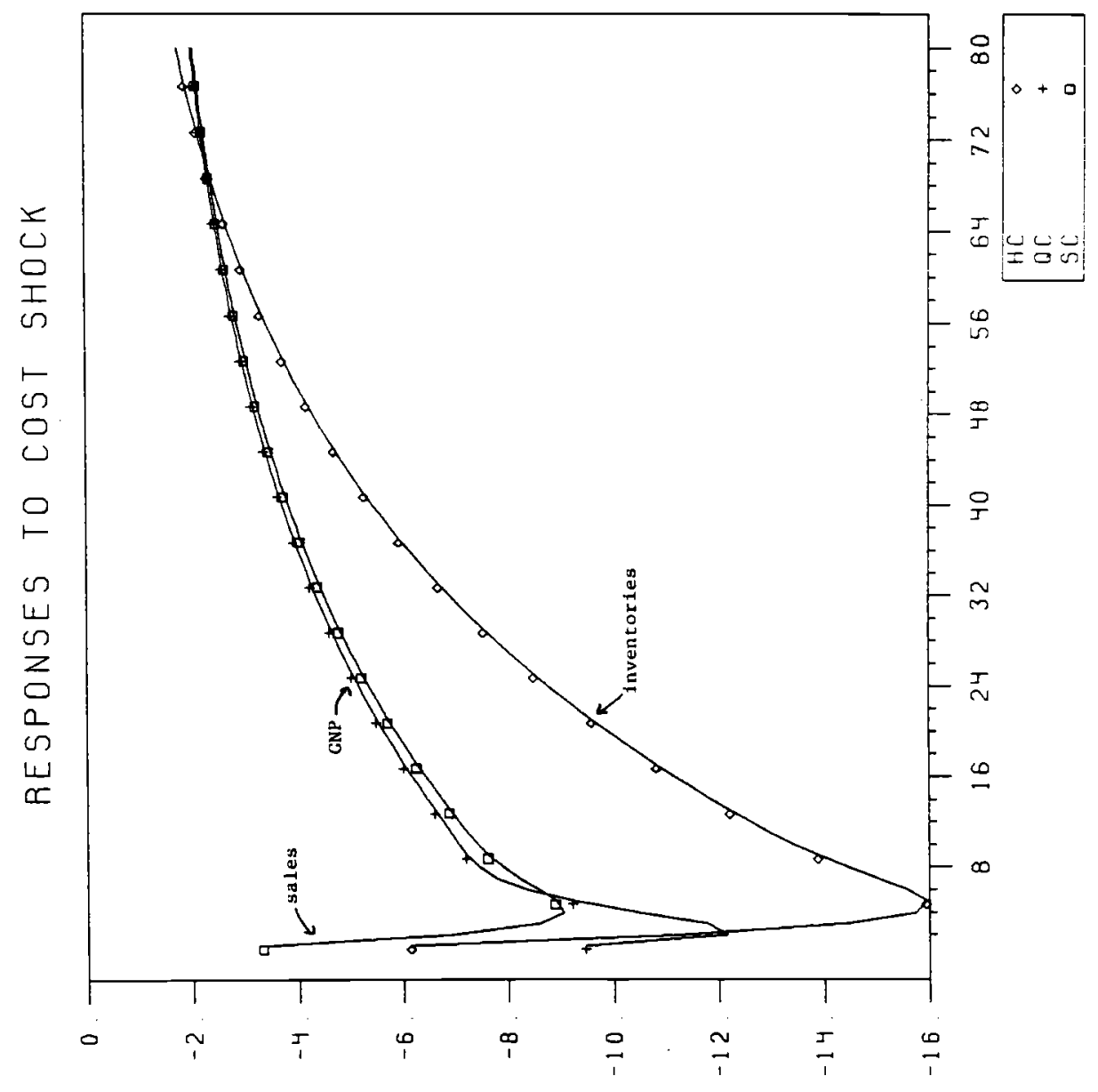




\section{References}

Belsley, David A., Industry Production Behavior: The Order-Stock Distinction, (Amsterdam: North Holland, 1969).

Blanchard, Olivier J., "The Production and Inventory Behavior of the American Automobile Industry," Journal of Political Economy XCI (1983), 365-400.

Blanchard, Olivier J. and Angelo Melino, "The Cyclical Behavior of Prices and Quantities: The Case of the Automobile Market," Journal of Monetary Economics XVII (1986), 379-408.

Blanchard, Olivier $J$. and Danny Quah, "The Dynamic Effects of Aggregate Demand and Supply Disturbances," National Bureau of Economic Research Working Paper No. 2737, 1988 .

Blanchard, Olivier J. and Mark W. Watson, "Are Business Cycles All Alike?", 123-156 in The American Business Cycle: Continuity and Change, Robert $J$. Gordon (ed.), (Chicago, IL: University of Chicago Press, 1986).

Blinder, Alan S., "Inventories and the Structure of Macro Models," American Economic Review LXXI (1981), $11 \cdot 16$.

Blinder, Alan S., "Inventories and Sticky Prices: More on the Microfoundations of Macroeconomics," American Economic Review LXXII (1982), 334-48.

Blinder, Alan S., "Can the Production Smoothing Model of Inventory Behavior be Saved?", The Quarterly Journal of Economics CI (1986a), 431-454.

Blinder, Alan S., "More on the Speed of Adjustment in Inventory Mode1s," Journal of Money. Credit and Bank1ng, XVIII(1986b), 355-65.

Blinder, Alan S. and Douglas Holtz-Eakin, "Inventory Fluctuations in the United States since 1929," 183-214 in The American Business Cycle, Robert $\mathrm{J}$. Gordon (ed.) (Chicago, IL: University of Chicago Press, 1986).

Christiano, Lawrence $J$. and Martin Eichenbaum, "Temporal Aggregation and the Stock Adfustment Model of Inventories," Federal Reserve Bank of Minneapolis Working Paper 357, 1987.

Efron, Bradley, The Jacknife, the Bootstrap and Other Resampling Plans, (Philadelphia, PA: Society for Industrial and Applied Mathematics, 1982).

Eichenbaum, Martin S., "Rational Expectations and the Smoothing Properties of Finished Goods Inventories," Journal of Monetary Economics XIV (1984), 271-96.

Engle, Robert F., and C.W. J. Granger, "Dynawic Model Specification with Equilibrium Constraints: Co-integration and Error Correction," Econometrica LV (1987), 251-276.

Fair, Ray C., The Specification and Estimation of Macroeconomic Models, (Cambridge, MA: Harvard University Press, 1984). 
Falr, Ray C., "The Sources of Economlc Fluctuations in the United States," Quarterly Journal of Economics CIII (1988), 313-332.

Freedman, David, On Bootstrapping Two Stage Least Squares Estimates in statlonary LInear Models," The Annals of Statistics XII (1982), 827-842.

Haltiwanger, John C. and Louls J. Maccinl, "The TIme Serles Properties of Aggregate Order, Inventorles and Labor Inputs, " unpublished manuscript, The Johns Hopkins UnIversity, 1987.

Hansen, Lars Peter, and Thomas J. Sargent, "Linear Rational Expectations Models for Dynamically Interrelated Varlables," 127-158 in Ratlonal Expectations and Econometrlc Practlce, Robert E. Lucas, Jr., and Thomas J. Sargent (eds) (MInneapolls, MN: University of Minnesota Press, 1981).

Holt, Charles C., Modigllanl, Franco, Muth, John and Herbert SImon, Planning Production. Inventories and Work Force, (Englewood Cliffs, N.J.: Prentice-Ha11, 1960).

Irvine, F. Owen, "Merchant Wholesalers Inventory and the Cost of Capital," Amerlcan Economlc Revlew LXXI (1981), 23-29.

King, Robert, Plosser, Charles, Stock, James and Mark Watson, "Stochastic Trends and Economlc Fluctuatlons," NBER Working Paper No. 2219, 1987.

Love11, Mlchael C., "Manufacturer's Inventorles, Sales Expectations, and the Accelerator Principle," Econometrica XXIX (1961), 293-314.

Maccinl, Louls J., and Robert Rossana, "Investment in Finished Goods Inventorles: An Analysis of Adjustment Speeds," American Economic Review LXXI (1981), 17-22.

Maccinl, Louis J., and Robert Rossana, "Jolnt Production, Quas1-Flxed Factors of Production and Investment In Finlshed Goods Inventorles, " Journal of Money, Credit and Banklng XVI (1984), 218-236.

Metzler, Lloyd M., "The Nature and Stabllity of Inventory Cycles," Review of Economics and Statistics XXIII (1941), 113-129.

Miron, Jeffrey A. and Stephen Zeldes, "Seasonality, Cost Shocks and the Production Smoothing Model of Inventorles," NBER Working Paper No. 2360, 1987.

Prescott, Edward C., "Response to a Skeptic," Federal Reserve Bank of Minneapolis Quarterly Review X (1986a), 28-33.

Prescott, Edward C., "Theory Ahead of Business Cycle Measurement," Federal Reserve Bank of Minneapolis Quarterly Review X (1986b), 9-22.

Ramey, Valerle A., "Non-Convex Costs and the Behavior of Inventories," manuscript, University of California at San Diego, 1988.

Runkle, Dav1d E., "Vector Autoregressions and Reallty," forthcoming, Journal of Economic and Business Statistics, 1987. 
Sald, Sald E. and David A. Dickey, "Testing for Unit Roots in Autoregressive Moving Average Models of Unknown Order, "Blometrika LXXI (1984), 599-607.

Sargent, Thomas J., Macroeconomic Theory (New York, NY: Academic Press, 1979).

Schutte, David P., "Inventorles and Sticky Prices: A Note," American Economic Review LXXXIII (1983), 815-816.

Schwert, G. William, "Tests for Unit Roots: A Monte Carlo Investigation," unpublished manuscript, University of Rochester, 1987.

Stengel, Robert F., Stochastic Optimal Control (New York, NY: John Wiley and Sons, 1986).

Summers, Lawrence H., "Comment," Brookings Papers on Economic Activity, $(1981: 2), 513-517$.

West, Kenneth D., "A Var1ance Bounds Test of the Linear Quadratic Inventory Model," Journal of Polltical Economy XCIV (1986), 374-401.

West, Kenneth D., "Order Backlogs and Production Smoothing," 305-318 in The Economics of Inventory Management, Michael Lovell (ed), (Amsterdam: Elsevier, 1988).

West, Kenneth D., "Dividend Innovations and Stock Price Volatility," Econometrica LVI (1988), 37-62. 
Table I

Estimates of Serial Correlation Parameters

(1) (2)

$$
\phi_{c} \phi_{d}
$$

(1) 1.0

1.0

(2) $0.949 \quad 0.949$

(3)
(3)

$F \Phi F^{-1}$

1.0

0.0

0.949

0.0

0.9690 .997 $\begin{array}{ll}0.976 & -0.005\end{array}$

$\begin{array}{rr}-0.027 & 0.990\end{array}$
(4)

Left Hand S1de Varlable in Regressions $\mathrm{H}_{\mathrm{q}}$

$H_{\varepsilon}-H_{t-1}$

$Q_{t}-Q_{t-1}$

$Q_{t}=0.949 Q_{t-1}$

$H_{t}-0.949 H_{t-1}$

$Q_{t}$
0.0

1.0

0.0

0.949

$H_{t-1}-0.976 H_{t-1}+.005 Q_{t-1} Q_{t}+.027 H_{t-1}-0.990 Q_{t-1}$ 


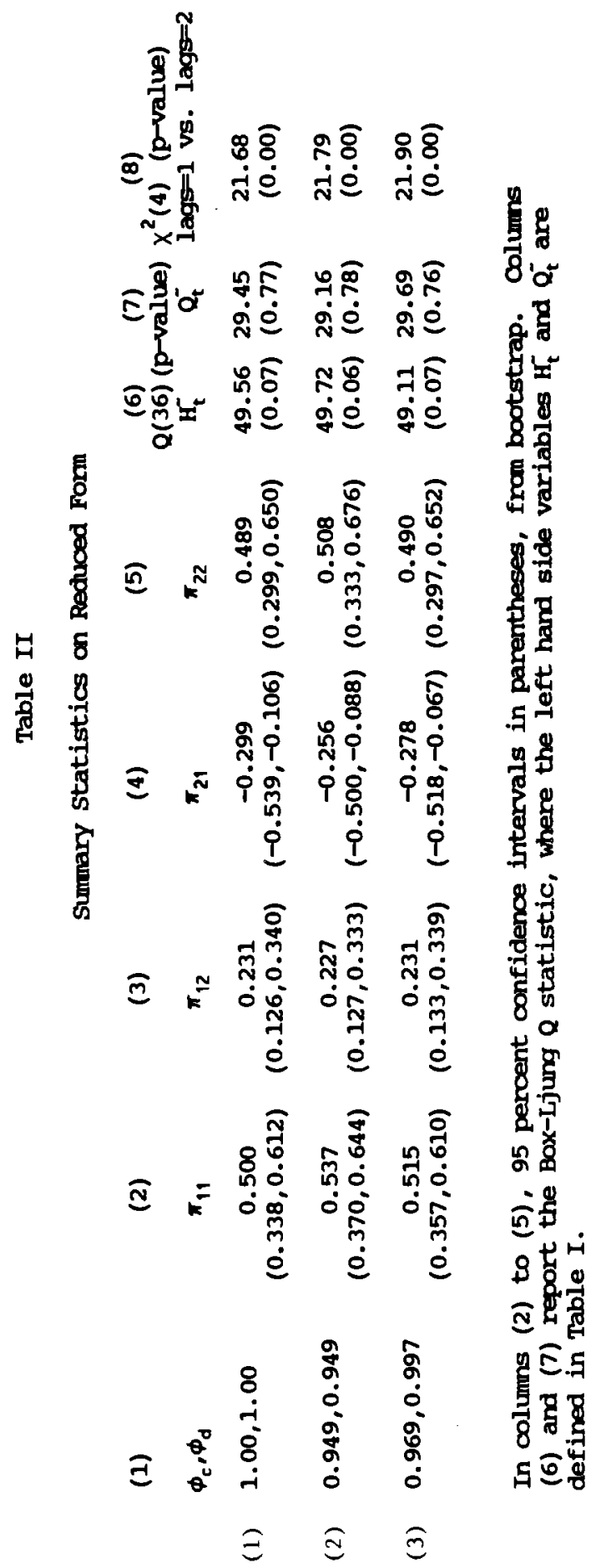




\section{Table III}

Estimates of Cost and Demand Parameters

(1)<smiles>[13CH3]</smiles>

$\phi_{\mathrm{e}}, \phi_{\mathrm{d}}$

(3)

(4)

(5)

(6)

$g_{10}$

gos

$g_{\text {OB }}$

(1)

$1.00,1.00$

$-0.072$

0.344

0.392

0.145

.0 .040 $(-0.320,0.232)(0.214,0.407)(0.111,0.657)(0.050 .0 .320)(-0.663,0.680)$

(2)
$0.949,0.949$

$-0.044$

0.366

0.317

0.111

$-0.127$

$(-0.303,0.260)(0.251,0.417)(0.074,0.589)(0.041,0.287)(-0.947,0.551)$

(3)

$0.969,0.997$

$-0.055$

0.347

0.367

0.129

$-0.057$

$(-0.315,0.218)(0.203,0.407)(0.108,0.625)(0.037,0.299)(-0.636,0.874)$

95 percent confidence intervals in parentheses, from bootstrap. The five parameters are related by the normalization $1=g_{0 S}+g_{00}+g_{08} g_{B S}^{2}+(1+b) g_{10}$. 
Table IV

Variability of GNP versus Final Sales

Specification

(1)

$\phi_{c}-\phi_{d}-1.00$
$E\left(S_{t}^{2}-Q_{t}^{2}\right)$

$-303.2$

$(-491.3,-161.7)$

$-13.4$

$(-241.8,70.0)$

(3) Just cost shocks

$$
-289.7
$$

$(-472.3,-58.1)$

(1) Raw data

(2) Just demand shocks
(2)

$\phi_{c}-\phi_{d}=0.949$

$\operatorname{var}(Q) / \operatorname{var}(S)$

1.09

$(1.06,1.14)$

1.002

$(0.90,1.05)$

1.17

$(1.09,1.40)$

95 per cent confidence intervals in parentheses, from bootstrap. For column $I$, units are billions of 1982 dollars squared. To interpret these entries, it may help to note that the values of $\operatorname{var}(\Delta Q)$ corresponding to the three lines in column 1 are $146.8,44.5$, and 101.2 . 
Table V

Percentage of Varlance Dus to Cost Shocks

Variable Horizon

H

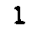

4

8

12

20

$\infty$

Q

$$
1
$$

4

8

12

20

$\infty$

s
(1)

$$
\phi_{c}-\phi_{d}=1.00
$$

89

$(64.7,99.9)$

97

$(74.0,99.7)$

98

$(68.1,99.5)$

99

$(66.7,99.6)$

100

$(65.6,99.7)$

100

$(64.5,100.0)$
Specification

(2)

$\phi_{c}=0.949$

77

$(60.3,98.2)$

94

$(75.5,98.9)$

97

$(78.2,99.2)$

98

$(78.3,99.4)$

98

$(78.2,99.4)$

98

$(78.0,99.5)$

83

$(47.0,94.8)$

71

$(31.4,90.4)$

63

(24.6.87.3)

60

58

$(21.7,85.0)$

57

$(21.3,84,4)$

22

$(1.0,48.1)$

51

(18.2,74.5)

$$
53
$$

$\phi_{c}=0.969, \phi_{d}=0.996$

83

$(60.6,99.9)$

96

$(60.5,99.3)$

99

$(51.6,99.4)$

99

$(48.7,99.5)$

99

$(46.1,99.6)$

93

$(36.7,98.5)$

$1,90.7)$

59
$(12.1,90.7$

(7. $2,78.4)$

48

$(5.8,69.4)$

43

$(4.4,66.0)$

37

(3.7,60.4)

13

$(2.9,34.9)$

15

$(0.1,41.1)$

39

$(4.2,59.7)$

38

4

$(4,2,61.3)$

41

$(19.1,78.8)$

53

$(19.0,80.0)$

53

$(3.7,64.9)$

$(3.6,66.2)$

41

$(18.7,81.3)$

53

$(18.8,81.7)$

$(2.9,61.4)$

36

(2.7,60.2)

33

$(2,4,57.1)$

12

$(2.3,34.3)$

$(3.2,68.2)$

95 percent confldence interval in parentheses, from bootstrap. For the column (1) specification ( 95 percent bootstrap confldence interval in parentheses), $h=0.81$ $(-0.38,4.70),\left(\sigma_{c} / \sigma_{d}\right)-0.85(0.07,2.03)$. For the column (2) specification, $h=0.65$ $(-0.14,2.87),\left(\sigma_{c} / \sigma_{d}\right)-1.16(0.07,9.86)$. For the column (3) specification, $h-0.71$ $(-0.41,3.97),\left(\sigma_{c} / \sigma_{d}\right)=0.92(0.09,1.94)$. 
Table VI

Estimates for Expanded Mode1, $\phi_{c}-\phi_{d}-1$

A. Estimates of Cost and Demand Parameters

$\begin{array}{lllllllll}B_{00} & g_{10} & g_{03} & g_{08} & g_{E A} & g_{20} & g_{1 B} & g_{2 B} & g_{1 B O} \\ .0 .222 & 0.453 & 0.323 & 0.099 & 0.118 & -0.088 & -0.003 & -0.045 & 0.115\end{array}$

B. Percentage of Variance Due to Cost Shocks

Horizon $\quad \mathrm{H} \quad \mathrm{Q} \quad \mathrm{S}$

$\infty \quad 99 \quad 45 \quad 45$

No confidence intervals availabie; $h-1.83,\left(\sigma_{c} / \sigma_{d}\right)-0.72$. 
Table VII

Percentage of Variance Due to Cost Shocks, $g_{B S}=.68, \phi_{c}-\phi_{d}-1$

$\begin{array}{llll}\text { Horizon } & \text { H } & \text { Q } & \text { S } \\ \infty & 66 & 9 & 9\end{array}$

No confidence intervals available; h- 4.98, $\left(\sigma_{e} / \sigma_{d}\right)=0.07$. 


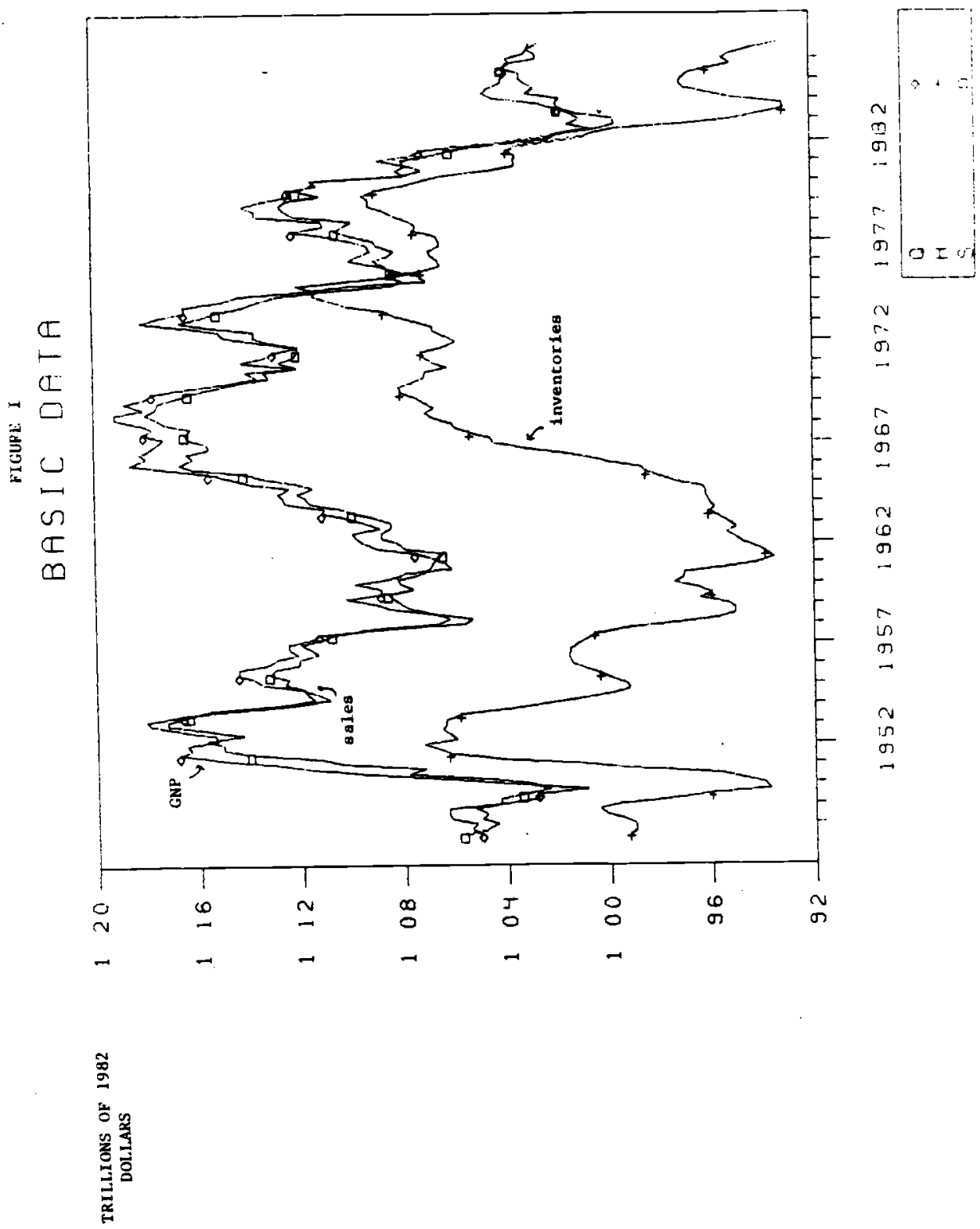




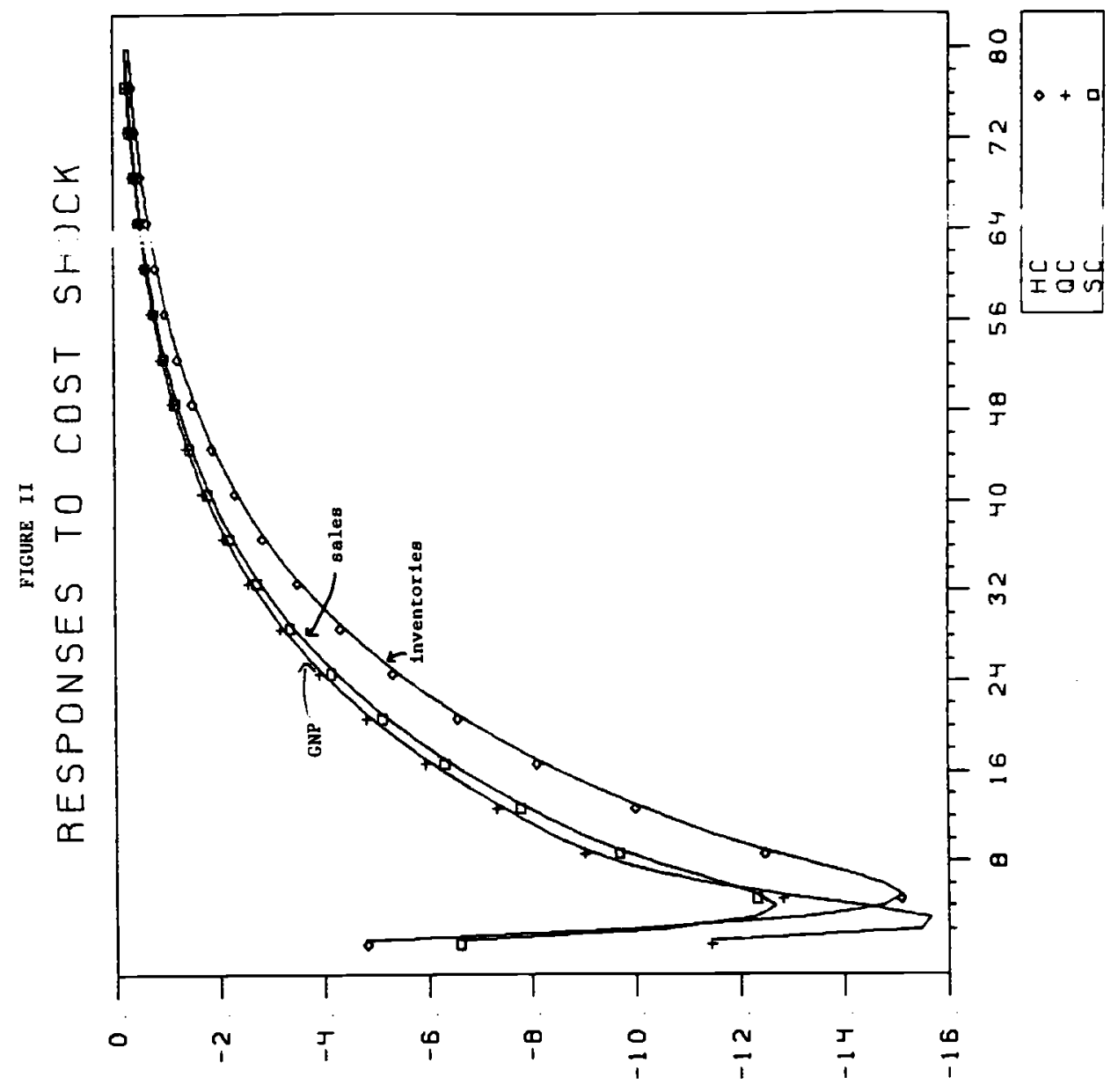




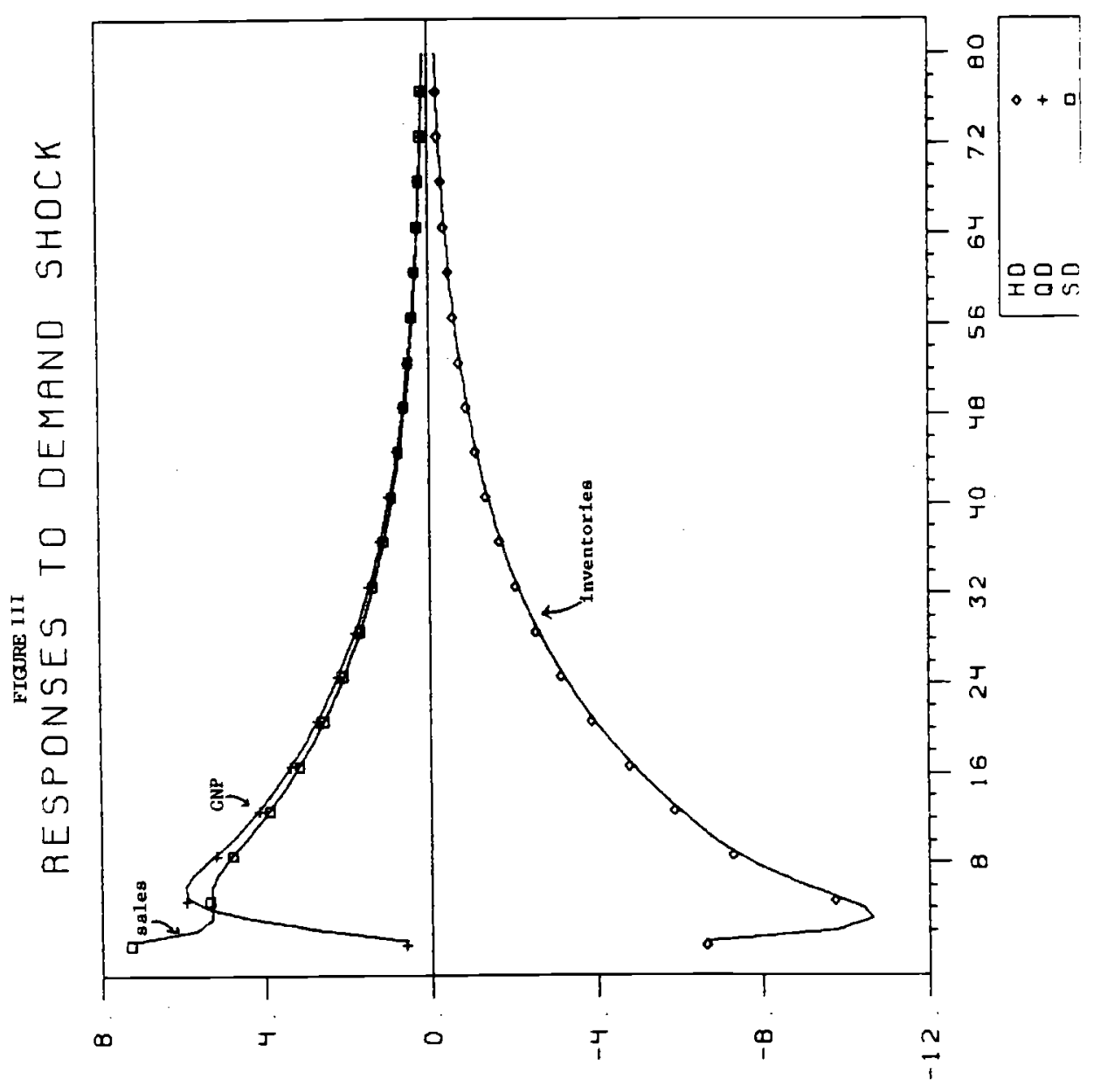




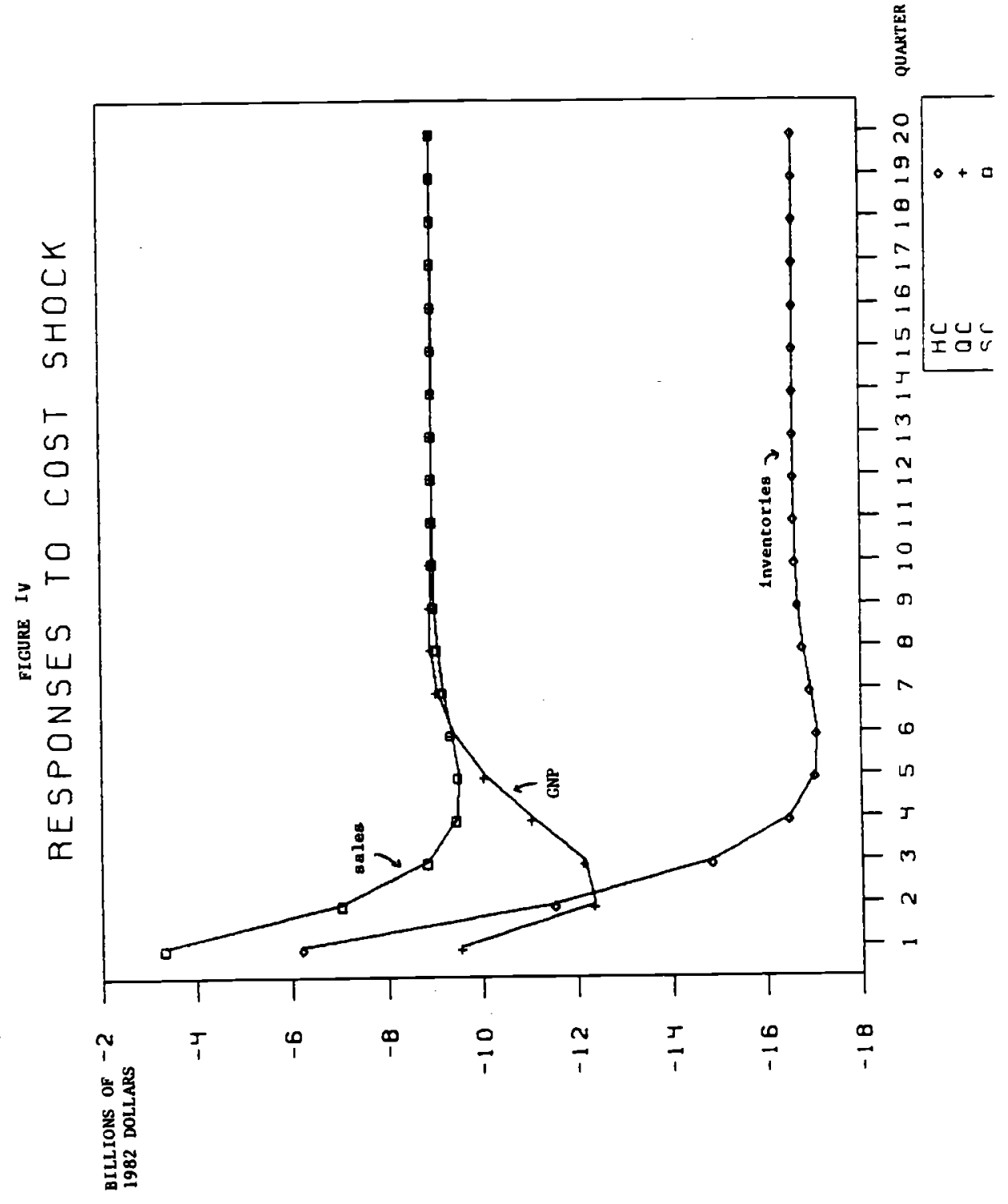




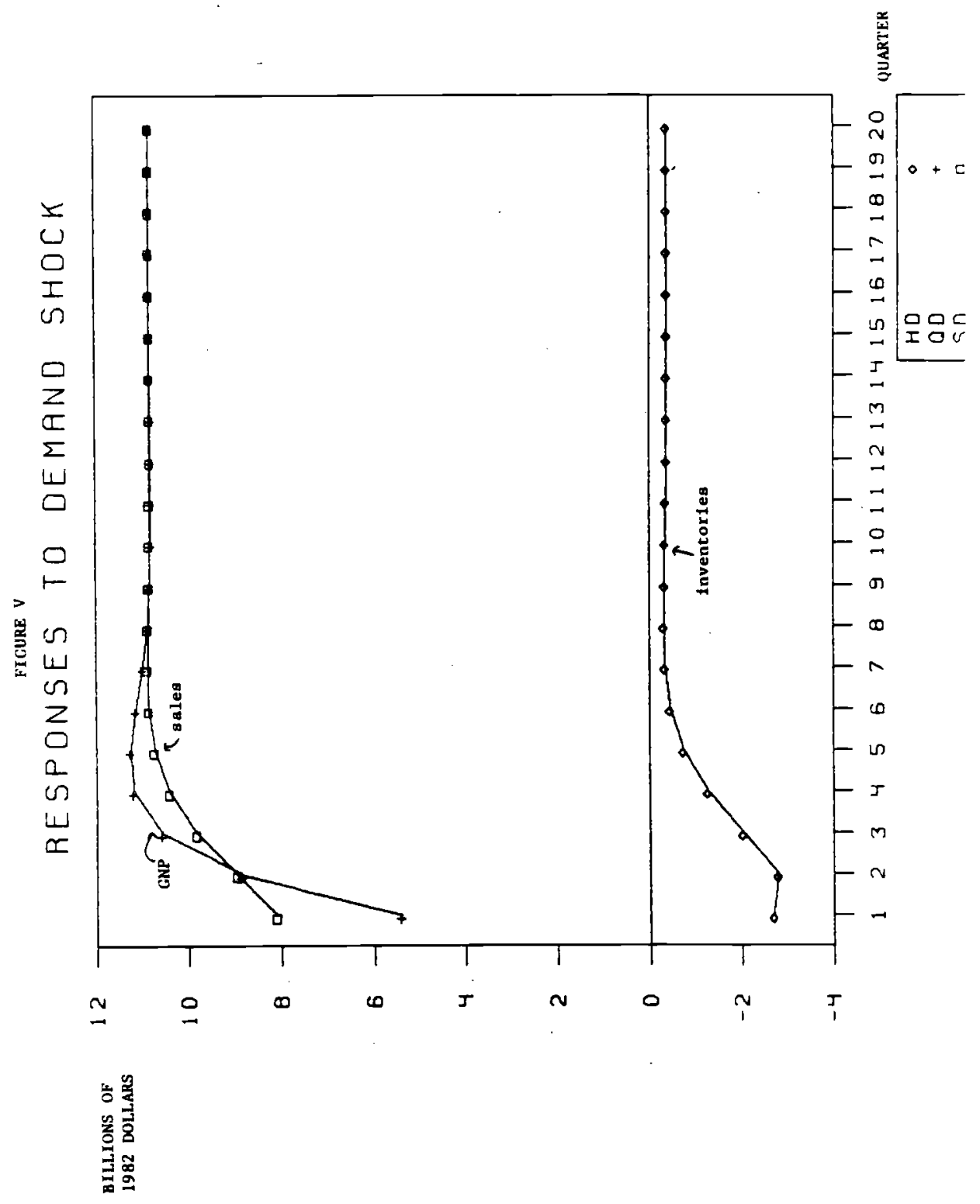

